Ann. Geophysicae 16, 866-881 (1998) @ C EGS - Springer-Verlag 1998

\title{
The effect of coastal upwelling on the sea-breeze circulation at Cabo Frio, Brazil: a numerical experiment
}

\author{
S. H. Franchito, V. B. Rao, J. L. Stech, J. A. Lorenzzetti \\ Instituto National de Pesquisas Espaciais, INPE, CP 515, 12201-970, São José dos Campos, SP, Brazil
}

Received: 20 June 1997 / Revised: 21 January 1998 / Accepted: 12 February 1998

\begin{abstract}
The effect of coastal upwelling on sea-breeze circulation in Cabo Frio (Brazil) and the feedback of sea-breeze on the upwelling signal in this region are investigated. In order to study the effect of coastal upwelling on sea-breeze a non-linear, three-dimensional, primitive equation atmospheric model is employed. The model considers only dry air and employs boundary layer formulation. The surface temperature is determined by a forcing function applied to the Earth's surface. In order to investigate the seasonal variations of the circulation, numerical experiments considering three-month means are conducted: January-FebruaryMarch (JFM), April-May-June (AMJ), July-AugustSeptember (JAS) and October-November-December (OND). The model results show that the sea-breeze is most intense near the coast at all the seasons. The seabreeze is stronger in OND and JFM, when the upwelling occurs, and weaker in AMJ and JAS, when there is no upwelling. Numerical simulations also show that when the upwelling occurs the sea-breeze develops and attains maximum intensity earlier than when it does not occur. Observations show a similar behavior. In order to verify the effect of the sea-breeze surface wind on the upwelling, a two-layer finite element ocean model is also implemented. The results of simulations using this model, forced by the wind generated in the sea-breeze model, show that the sea-breeze effectively enhances the upwelling signal.
\end{abstract}

Key words. Meteorology and atmospheric dynamics (mesoscale meteorology; ocean-atmosphere interactions) · Oceanography (numerical modeling)

\section{Introduction}

The best known regions of coastal upwelling are located in the eastern margins of the world oceans, e.g. in Peru, Ecuador, California and Oregon on the Pacific Ocean coast, and northwest Africa and southern Benguela current on the Atlantic Ocean coast. This oceanographic phenomenon is of fundamental importance for the maintenance of the high biological productivity of these regions. Although less intense, coastal upwelling is also present at some coastal regions located at the western margins of the oceans. For example, during the summer period a coastal upwelling is observed at Cape Canaveral in the southeastern continental shelf of the United States (Lorenzzetti et al., 1987).

Along part of the Brazilian southeast continental shelf, and particularly near Cabo Frio $\left(22^{\circ} 59^{\prime} \mathrm{S}\right.$, $42^{\circ} 02^{\prime} \mathrm{W}$ ) (Fig. 1), a seasonal upwelling is present during the spring and summer months. During the fall and winter seasons, there is a relaxation of the upwelling (Stech et al., 1995). The upwelling at Cabo Frio is another example of this phenomenon occurring on the west coast of oceans. Considering that the surface layers of this region are dominated by warm waters of tropical origin, with low levels of productivity, the observed coastal upwelling is of great importance for the biological enrichment of the water and sustaining of the fishery activities of this region. Studies using ship, coastal stations data and infrared satellite images have shown that strong negative sea surface temperature (SST) anomalies are present during most of the year in this region (Lorenzzetti et al., 1988; Valentin, 1984; Miranda, 1982). In particular, the infrared images from the NOAA satellites have shown that coastal upwelling occurs from the coast of Espirito Santo state, north of Cabo Frio, to the region near Guanabara Bay, with the largest negative SST anomalies occurring along the coast near the Capes of São Tomé, Búzios and Frio (Humi and Lorenzzetti, 1991). Figure 2 shows a NOAA- 


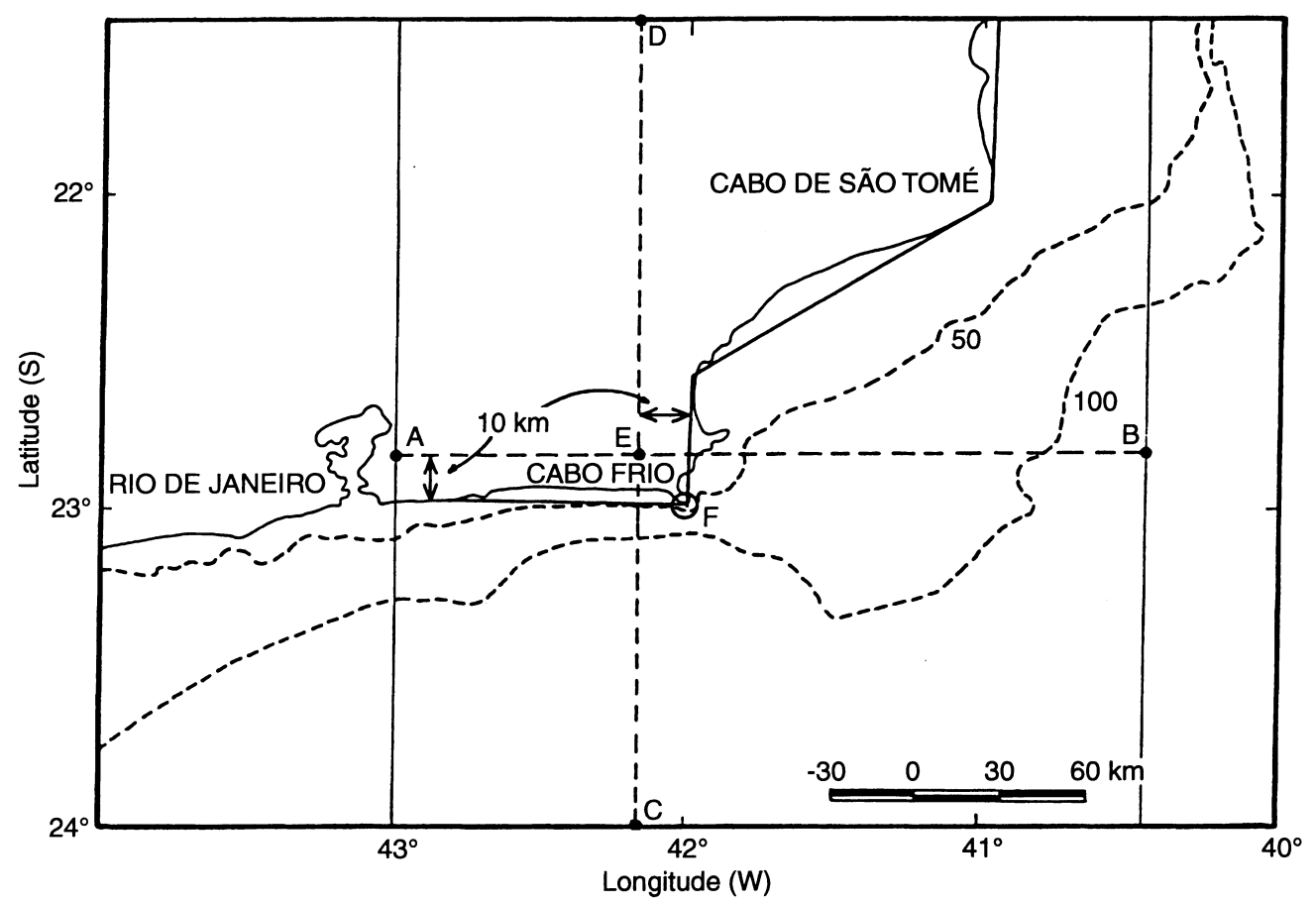

Fig. 1. Region of Cabo Frio. The coastline considered in the model is indicated by a thick line. The smaller rectangle represents the model domain. The dashed lines represent the isobaths in $\mathrm{m}$. The line $A B$ indicates grid-points along a parallel line $10 \mathrm{~km}$ northward from the EW coast; the line $C D$ corresponds to grid-points along a parallel line $10 \mathrm{~km}$ westward from the NS coast; the point $E$ represents a gridpoint situated $10 \mathrm{~km}$ inland from both the EW and NS coastlines; $F$ indicates the interception of the EW and NS coastlines. These lines and points are useful for analyzing the model results

12 AVHRR satellite image that illustrates the presence of negative SST anomalies in this region.

It has been speculated that the seasonality of the Cabo Frio upwelling is associated with the onshore/ offshore seasonal migration of the South Atlantic
Central Water (SACW) at the continental slope. Recent studies have shown that the SACW is the source of the cold waters that crop up near the coast in this region (Gaeta et al., 1994; Valentin, 1984). Sometimes when strong NE winds persist for several days, strong

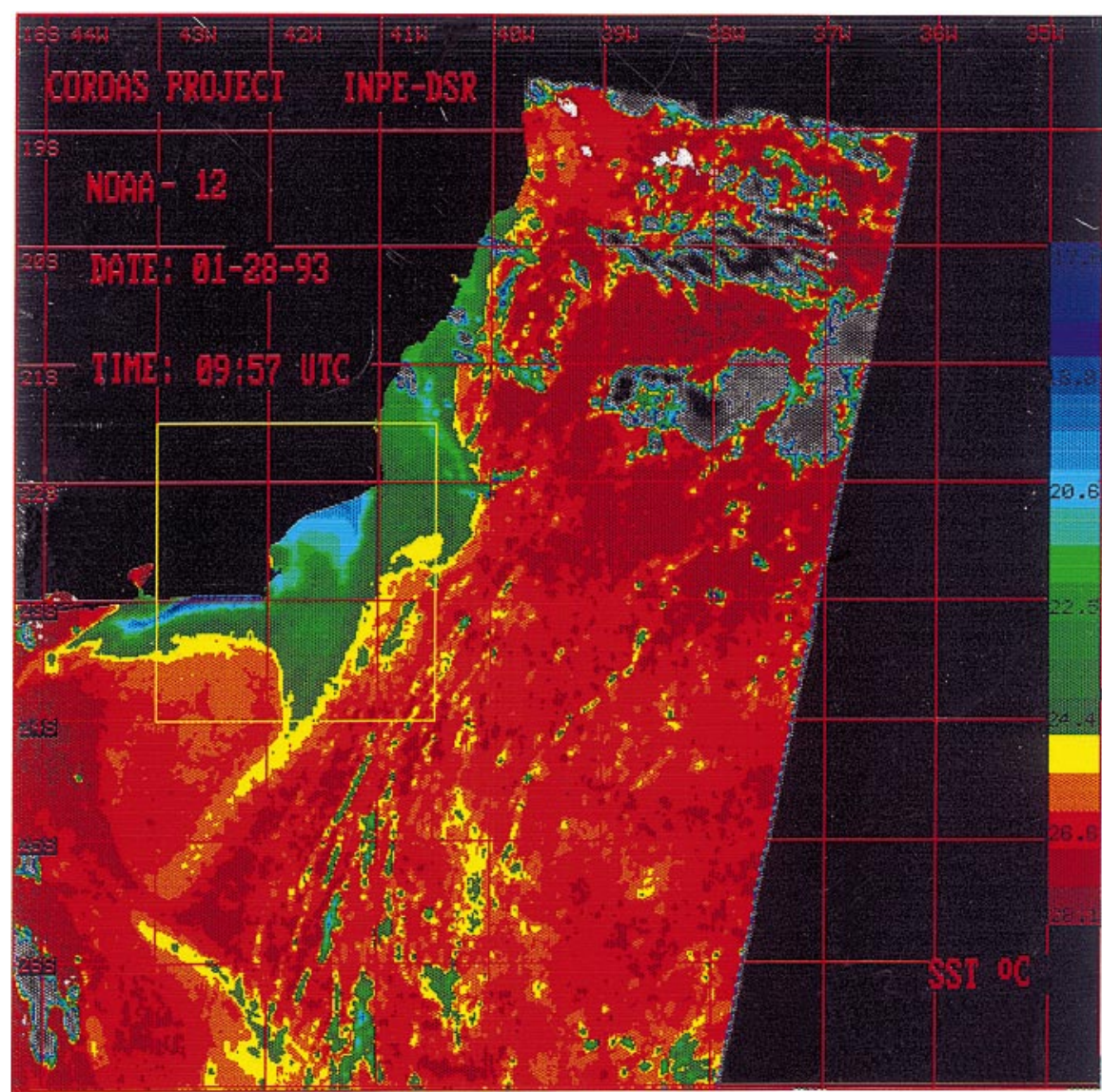

Fig. 2. Sea surface temperature satellite image showing the coastal upwelling in the Cabo Frio region. The yellow square represents the model domain 
upwelling can develop with surface temperatures dropping to $13-14^{\circ} \mathrm{C}$ near the coast, close to Cabo Frio. These temperatures are about $10^{\circ} \mathrm{C}$ cooler than the midand outer shelf waters. On the synoptic time scale of 6 11 days, as cold fronts pass over the region, the surface winds rotate counterclockwise and blow for a few days from the southern quadrant, inhibiting the upwelling.

The large-scale atmospheric high pressure center located over the South Atlantic ocean makes the prevailing surface wind blow from the northeast along the Brazilian coast near Cabo Frio (Stech and Lorenzzetti, 1992). The southwest-northeast and east-west orientation of the coastline in this region (Fig. 1), favors the development of a strong alongshore wind stress component, which is the main forcing of this upwelling.

Most of the Brazilian coastal regions are influenced by the sea-breeze circulation which occurs due to the horizontal temperature difference between the land and the ocean. Since the land is warmer than the ocean during the day, the local surface wind blows from sea to land (sea-breeze); at higher altitude, there is a weaker return flow, which blows from land to sea. The circulation is opposite during the night because the land is colder than the ocean (land breeze). These local winds may have an important role in determining the climate in coastal regions because they influence the characteristic air flow, the precipitation and the humidity and pollutant transports ( $\mathrm{Lu}$ and Turco, 1994; Kousky, 1980; Anthes, 1978; Ramos, 1975).

The sea-breeze circulation may be stronger when coastal upwelling is present because the negative SST anomalies increase the horizontal temperature difference between the ocean and land. The sea-breeze circulation in turn modulates the coastal ocean circulation. Preliminary analysis of coastal wind time series clearly shows a strong sea-breeze near Cabo Frio, as noted in Fig. 3. Thus, the coastal upwelling should intensify the oceanatmosphere interaction processes in this region whose consequences are not yet known.

The objective of the present work is to study the influence of the coastal upwelling on the local atmospheric circulation in the region of Cabo Frio and to verify the feedback of the sea-breeze on the upwelling signal. Basically, we propose to conduct a numerical simulation of the sea-breeze circulation forced by the characteristic SST of this region. The upwelling occurs mainly in austral summer and it is practically absent in winter. Numerical experiments using the atmospheric model will be carried out separately for three-month mean conditions: January-February-March (JFM), April-May-June (AMJ), July-August-September (JAS) and October-November-December (OND), in order to study the seasonal variations in the sea-breeze circulation of this region. The influence of the breeze on the upwelling is investigated using a numerical ocean model. These two models are described in Sect. 2; the model results and comparisons with observations are discussed in Sect. 3; and the summary and conclusions are presented in Sect. 4.

\section{The numerical models}

\subsection{The sea-breeze model}

The atmospheric model developed for this study is a three-dimensional, non-linear, primitive equation model for dry air. This model is a three-dimensional version of the two-dimensional model developed by Franchito and Kousky (1982).

The hydrodynamical equations, the structure of the horizontal and vertical grids and the temporal integration scheme are based on the mesoscale model developed by Anthes and Warner (1978). However, simplifications are made in the parametrizations of the surface diurnal heating and the planetary boundary layer. Since the model of Franchito and Kousky (1982) was published in a journal of limited circulation, a detailed description is given below.

2.1.1 Basic equations. The equations are written in a $(x, y, \sigma, t)$ system, where $x$ and $y$ are the west-east and south-north directions, respectively, and $\sigma$ is the vertical coordinate given by:

$\sigma=\left(p-p_{t}\right) / p^{*}$

where $p^{*}=p_{s}-p_{t} ; p_{s}$ is the surface pressure; $p_{t}$ the pressure at the top of the model $(500 \mathrm{hPa})$; and $p$, the pressure at some level of the model.

The momentum, continuity, hydrostatic and thermodynamic equations are given, respectively, by:

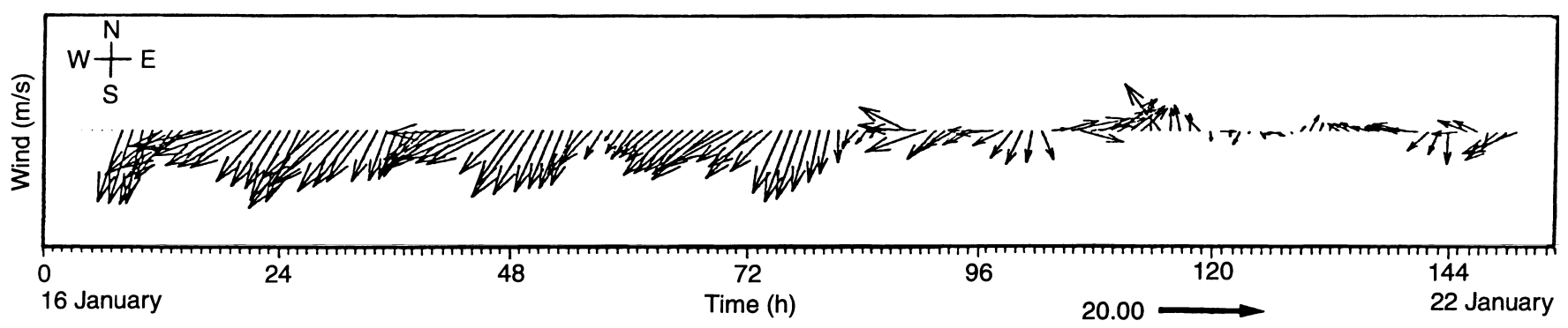

Fig. 3. Diurnal variations of the horizontal surface wind-vector near the coast in Cabo Frio $\left(22^{\circ} 59^{\prime} \mathrm{S}, 42^{\circ} 02^{\prime} \mathrm{W}\right)$. Data are from Operation Cabo Frio 8 conducted by the Brazilian Navy in 16-22 January 1986. Units are $\mathrm{m} \mathrm{s}^{-1}$ 


$$
\begin{aligned}
\partial\left(p^{*} u\right) / \partial t=- & \partial\left(p^{*} u u\right) / \partial x-\partial\left(p^{*} v u\right) / \partial y-\partial\left(p^{*} u \dot{\sigma}\right) / \partial \sigma \\
& +p^{*} f v-p^{*}\left[(R T) /\left(p^{*}+p_{t} / \sigma\right) \partial p^{*} / \partial x\right. \\
& +\partial \phi / \partial x]+F U \\
\partial\left(p^{*} v\right) / \partial t=- & \left.\partial\left(p^{*} u v\right) / \partial x-\partial\left(p^{*} v v\right) / \partial y-\partial p^{*} v \dot{\sigma}\right) / \partial \sigma \\
& -p^{*} f u-p^{*}\left[(R T) /\left(p^{*}+p_{t} / \sigma\right) \partial p^{*} / \partial y\right. \\
& +\partial \phi / \partial y]+F V \\
\partial p^{*} / \partial t=-\left[\partial\left(p^{*} u\right) / \partial x+\partial\left(p^{*} v\right) / \partial y\right]-\partial\left(p^{*} \dot{\sigma}\right) / \partial \sigma, & \\
\partial \phi / \partial \ln (\sigma+ & \left.p_{t} / p^{*}\right)=-R T \\
\partial\left(p^{*} T\right) / \partial t=- & \left.\partial\left(u p^{*} T\right) / \partial x-\partial\left(v p^{*} T\right) / \partial y\right)-\partial\left(p^{*} T \dot{\sigma}\right) / \partial \sigma \\
& +R T \omega /\left[c_{p}\left(\sigma+p_{t} / p^{*}\right)\right]+F T
\end{aligned}
$$

The equation of the tendency of pressure is obtained through the integration of the continuity equation from the surface to the top of the model. So,

$\partial p^{*} / \partial t=-\int\left[\partial\left(p^{*} u\right) / \partial x+\partial\left(p^{*} v\right) / \partial y\right] \mathrm{d} \sigma$

where

$\omega=\mathrm{d} p / \mathrm{d} t$

and $(F \mathbf{U}, F \mathbf{V})$ are the frictional accelerations in $(x, y)$ direction and $F T$ is the temporal rate of change of $\left(p^{*} T\right)$ due to lateral and vertical diffusion of heat. The symbols have their usual meanings and are defined in Appendix A.

\subsubsection{Structures of the horizontal and vertical grids. The} horizontal and vertical grid structures are similar to those used by Anthes and Warner (1978). The horizontal grid is staggered, with the horizontal velocity components defined at the grid points $x_{i}=(i-1) \Delta x$ and $y_{j}=(j-1) \Delta y$, and all the other variables are defined at the grid points $x_{i+1 / 2}=(i-1 / 2) \Delta x$ and $y_{j+1 / 2}=(j-1 / 2) \Delta y$.

The vertical grid for our three-dimensional version of the model is also staggered, with the values of the horizontal velocity components, geopotential and temperature defined at the levels which are adjacent to the levels where $\dot{\sigma}$ is defined $(1015,1000,980,960,940,900$, $850,700,500 \mathrm{hPa}$ ). Figure 4 illustrates the structures of horizontal and vertical model grids. The grid intervals $\Delta x$ and $\Delta y$ are $10 \mathrm{~km}$.

The first level of the model where Eqs. (2), (3) and (6) are applied in order to obtain the fields of velocity components $(\mathbf{u}, \mathbf{v})$ and the temperature $(T)$ is $990 \mathrm{hPa}$ (which is around $200 \mathrm{~m}$ ). The values of these variables at the lowest level above surface $(1007.5 \mathrm{hPa})$ are calculated using a logarithmic interpolation.

2.1.3 Initial conditions. The SST is almost constant during the day compared to the land surface temperature (LST) because the heat capacity of sea water is large and the thermal mixing is very intense in the sea. Hence, the SST is assumed constant during the model integration. The diurnal change of LST is given by:
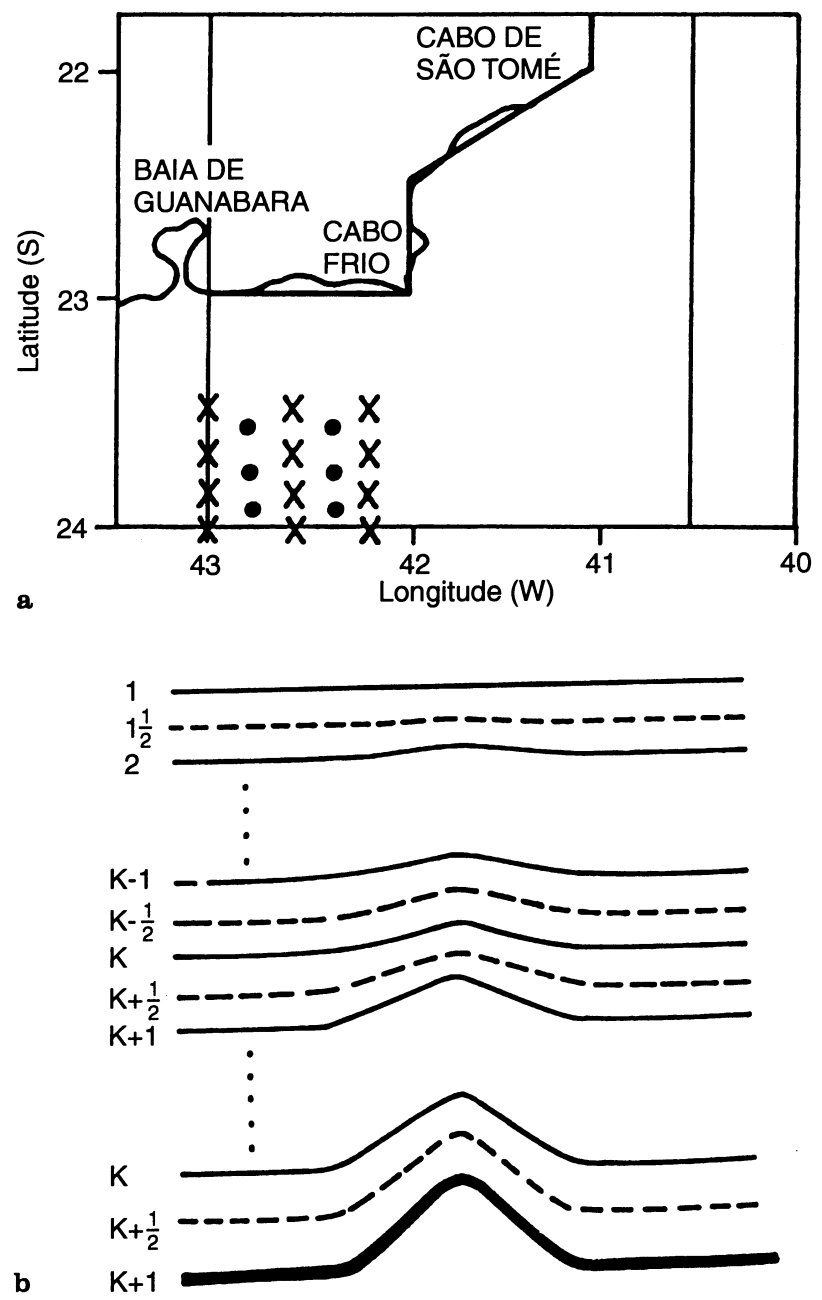

Fig. 4a,b. Structure of the model grid: a horizontal: the horizontal velocity components are defined at the cross-points, and all the other variables are defined at the dot points; $\mathbf{b}$ vertical: the vertical velocity is defined at the levels of the model (solid lines), and all the other variables are defined at the intermediate levels (broken lines)

$f(t)=5 \sin (2 \pi t / \tau)+1.7 \sin [4 \pi(t-2) / \tau]$.

Expression (9) has a general form of the diurnal variation of temperature: a maxima around 14:00 LT and a minima around 06:00 LT. The LST is assumed equal to SST at the beginning of the model integration $\left(t=t_{0}\right)$. Since the values of LST are different from those of SST (Table 1) it is necessary to obtain the value of $t$ which represents the difference between LST and SST $(\Delta T)$. The value of $t$ which corresponds to $f(t)=0$ is assumed as the initial time of integration. If this difference is negative (positive) the value of LST is lower (higher) than SST by the $\Delta T$, so that the abscissa in Fig. 5 must be moved up (down) by $|\Delta T|$ to make $f(t)=0$. The value of $t$ whose value of $f(t)=0$ is $t_{0}$. Because of the values of LST and SST (and consequently $|\Delta T|$ and $t_{0}$ ) depend on season, the diurnal variation of temperature has a seasonal component.

Since LST $=$ SST at $t=t_{0}$, the sea-breeze circulation has not set in yet. Thus, as an initial state the atmosphere is assumed to be at rest $(\mathbf{u}=\mathbf{v}=0)$ and in a stable equilibrium. The initial profile of temperature 
Table 1. Values of LST, SST, $\Delta T=\mathrm{LST}-\mathrm{SST}, t_{0}$ (initial time of integration), and the local time which corresponds to $t_{0}$ for threemonth-averages: JFM, AMJ, JAS and OND in the region of Cabo Frio. The SST and LST data are obtained from DHN and INMET, respectively

\begin{tabular}{lllllr}
\hline & $\begin{array}{l}\text { LST } \\
\left({ }^{\circ} \mathrm{C}\right)\end{array}$ & $\begin{array}{l}\mathrm{SST} \\
\left({ }^{\circ} \mathrm{C}\right)\end{array}$ & $\begin{array}{l}\Delta \mathrm{T} \\
\left({ }^{\circ} \mathrm{C}\right)\end{array}$ & $\begin{array}{l}t_{0} \\
(\mathrm{~h})\end{array}$ & \multicolumn{1}{l}{$\begin{array}{l}\text { Local time } \\
(\mathrm{h})\end{array}$} \\
\hline JFM & 25.1 & 23.6 & +1.5 & -0.02 & $9: 00 \mathrm{am}$ \\
AMJ & 22.5 & 22.9 & -0.4 & 1.0 & $\begin{array}{r}10: 00 \mathrm{am} \\
\text { JAS }\end{array}$ \\
OND & 23.9 & 20.5 & +0.4 & -1.0 & $\mathrm{am}$ \\
& 23.0 & 18.9 & +4.1 & -4.8 & $4: 12 \mathrm{am}$ \\
\hline
\end{tabular}

is the same over both land and sea, and it is obtained from climatological values.

2.1.4 Boundary conditions. The boundary conditions are similar to those used by Ookouchi et al. (1978).

$\mathbf{V}=0, \dot{\sigma}=0$

at the surface and top of the model because the effect of the prevailing wind is not considered. Laterally, it is assumed:

$\partial\left(p^{*}, T, \mathbf{V}\right) / \partial x=\partial\left(p^{*}, T, \mathbf{V}\right) / \partial y=0$.

The boundary conditions should not cause serious errors in the model results if the area of the domain of integration is sufficiently large.

2.1.5 Boundary layer parametrization. The model planetary boundary layer parametrization is similar to that proposed by Ookouchi et al. (1978). The heat and momentum diffusion processes are taken into account by using different coefficients for unstable and stable stratifications.

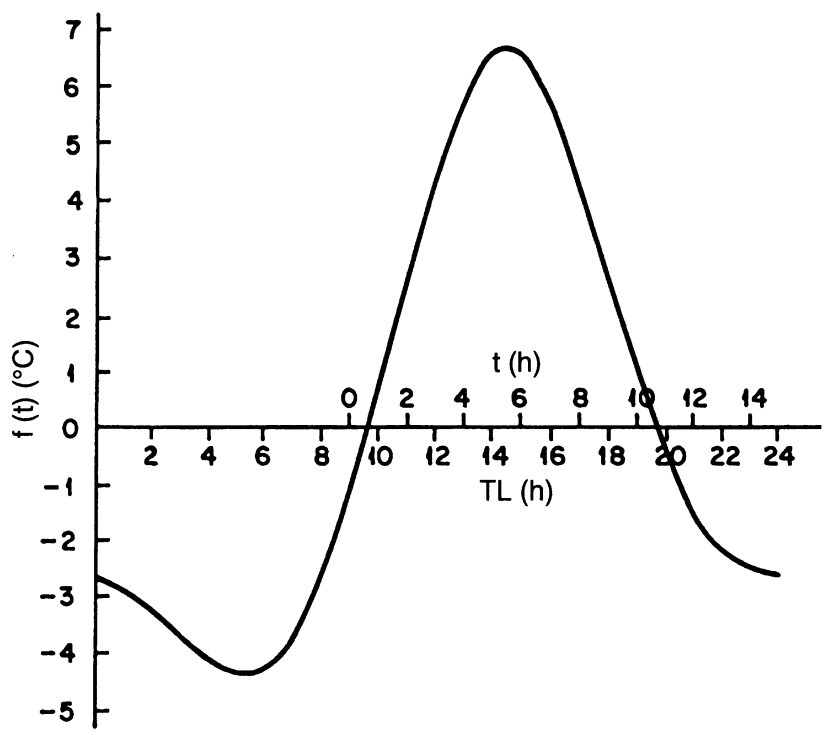

Fig. 5. Diurnal change of land surface temperature $f(t)$. The value $t=0$ corresponds to 9:00 LT. Units are ${ }^{\circ} \mathrm{C}$
In the case of unstable stratification, after KEYPS (Yamamoto, 1959), the eddy coefficient for momentum $K_{m}$ is given by:

$K_{m}=1^{2}\left[(\partial u / \partial z)^{2}+\alpha g / \theta_{a}|\partial \theta / \partial z|\right]^{1 / 2}$

where 1 is the mixing-length; $\theta_{a}$, a constant representing potential temperature $(290 \mathrm{~K})$; and $\alpha=K_{h} / K_{m}$. Although $\alpha$ is generally considered to be a function of the Richardson number and others, it does not deviate very much from 1 in the terrestrial atmosphere. Therefore, $\alpha$ is assumed to be equal to 1 and $K_{m}=K_{h}$. Since the effect of the general wind is not considered, the first term of Eq. (12) (vertical wind shear) is small. Thus, Eq. (12) becomes:

$K_{m}=K_{h}=1^{2}\left[g / \theta_{a}|\partial \theta / \partial z|\right]^{1 / 2}$.

The mixing-length 1 is assumed to be constant in the model because its value is almost constant above $100 \mathrm{~m}$ (Blackadar, 1962). The value of 1 is determined from the criterion of convective instability. The critical Rayleigh (Ra) number is about 660 under free boundary conditions (Chandrasekhar, 1961). Thus,

$$
\begin{aligned}
\mathrm{Ra} & =g / \theta_{a}|\partial \theta / \partial z| H^{4} / K_{m} K_{h} \\
& =g / \theta_{a}|\partial \theta / \partial z| H^{4} /\left(g / \theta_{a}|\partial \theta / \partial z| 1^{4}\right)=660 .
\end{aligned}
$$

The depth of the unstable layer $H$ is about $200 \sim 300 \mathrm{~m}$. If a mean value $(H=250 \mathrm{~m})$ is considered, the corresponding value of 1 is $50 \mathrm{~m}$, which is used in the model.

In the case of stable stratification, Eq. (12) is not a good approximation. Then, it is assumed that $K_{m}=$ $K_{h}=5 \mathrm{~m}^{2} \mathrm{~s}^{-1}$.

2.1.6 Temporal integration scheme. The temporal integration scheme is that developed by Shuman (1971) and generalized by Brown and Campana (1978). In this scheme the values of $p^{*}$ and $\phi$ are calculated before computing $\mathbf{u}$ and $\mathbf{v}$ values. Then, the weighted average of $p^{*}$ and $\phi$ at the time steps $(n-1),(n)$ and $(n+1)$ are used in the pressure gradient terms of the momentum equations. These averages are made as following:

$\eta^{(n)}=\xi\left(\eta^{(n-1)}+\eta^{(n+1)}\right)+(1-2 \xi) \eta^{(n)}$

where $\eta$ refers to $p^{*}$ and $\phi$.

This scheme allows for a time step 1.6 to 2 times larger than that allowed by the conventional leap-frog scheme and it is stable for $\xi \leq 0.25$. The value of $\xi=0.2495$ is used in the present model, as in Anthes and Warner (1978).

Although this scheme is stable for $\xi \leq 0.25$ the computational mode may become noticeable for long integrations. In order to avoid the growth of these errors, a temporal smoothing operator is applied at each 100 time steps:

$\eta^{(n)}=\left(\eta^{(n+1)}+\eta^{(n-1)}+2 \eta^{(n)}\right) / 4$ 
where $\eta$ refers to the model prognostic variables. This temporal smoothing operator is also applied to the time step $(n-1)$.

2.1.7 Source of data. SST data were obtained from the National Center of Oceanographic Data at the Hydrography and Navigation Directory (Centro Nacional de Dados Oceanográficos, Directoria de Hidrografia e Navegação - DHN) of the Brazilian Navy. These SST data correspond to three-month mean values (JFM, AMJ, JAS and OND) from 1957 to 1982. The LST data were obtained from the Center for Climate Analysis at the National Institute of Meteorology of Brazil (Instituto Nacional de Meteorologia - INEMET) and represent monthly means for the period from 1931 to 1960. These data were used to obtain the LST mean values for JFM, AMJ, JAS, and OND. The mean SST and LST values are given in Table 1 . As can be noted, the thermal contrast between land and ocean is larger in OND and JFM (when there is upwelling) and smaller in the winter months (when there is no upwelling).

The initial vertical air temperature profile used in the model refers to climatological values for JFM, AMJ, JAS and OND (averages for the period 1969-1976) for Galeão $\left(22^{\circ} 49^{\prime} \mathrm{S}, 43^{\circ} 15^{\prime} \mathrm{W}\right)$ obtained from the Monthly Climatic Data for the World. These vertical profiles of temperature correspond to stable equilibrium states of the atmosphere.

\subsection{The ocean model}

The ocean model used for the study of the upwelling derives from a finite element formulation by Wang and Connor (1975) and consists of two layers with constant but different densities. The advective terms are ignored based mostly on the small velocities present. The model formulation does not allow for interface outcropping or the collapse of the lower layer. When this happens the computations must be terminated. Arbitrary bottom topography can be included by specifying depths at element nodes. Vertically integrated equations of motion are derived for each layer which are solved in a Cartesian coordinate system with positive $z$ upwards. The following equations of continuity and momentum are used:

$$
\begin{aligned}
\partial H_{i} / \partial t+\partial q_{i x} / \partial x+ & \partial q_{i y} / \partial y=0, \\
\partial q_{i x} / \partial t-f q_{i y}=- & \partial\left(F_{i p}-F_{i x x}\right) / \partial x+\partial F_{i y x} / \partial y \\
& +\frac{1}{\rho_{i}}\left\{\tau_{i x}-\tau_{(i-1) x}+p_{i} \partial \xi_{i} / \partial x\right. \\
& \left.-p_{(i-1)} \partial \xi_{(i-1)} / \partial x\right\}, \\
\partial q_{i y} / \partial t+f q_{i x}=- & \partial\left(F_{i p}-F_{i y y}\right) / \partial y+\partial F_{i x y} / \partial x \\
& +\frac{1}{\rho_{i}}\left\{\tau_{i y}-\tau_{(i-1) y}+p_{i} \partial \xi_{i} / \partial y\right. \\
& \left.-p_{(i-1)} \partial \xi_{(i-1)} / \partial y\right\} .
\end{aligned}
$$

Subscript $i$ is 1 or 2 for lower or upper layers, respectively; $H$ is layer thickness; $u$ and $v$ are fluid velocities; $q_{x}$ and $q_{y}$ are layer-integrated volume transports; $f$ is the Coriolis parameter; $\rho$ is the layer density; $\xi_{0}$ is bottom elevation, $\xi_{1}$ is the interface elevation and $\xi_{2}$ is the surface elevation; $p_{0}$ is the bottom pressure; $p_{1}$ is the interface pressure, $p_{2}$ is the atmospheric pressure (here assumed equal to zero), $\tau$ is the bottom, interface, or surface shear stress; $F_{x x}, F_{y x}, F_{y y}$, are internal momentum exchanges; and $F_{i p}=\frac{1}{2} g H_{i}^{2}+\rho_{i}^{-1} p_{i} H_{i}$.

The density difference reflects a temperature change between the two layers. This density difference admits a baroclinic mode in the model and to some extent controls the internal wave characteristics. Mixing between layers is ignored and thus the densities remain constant at values typical of hydrographic data. The bottom and interface stresses are parametrized, respectively, as

$$
\begin{aligned}
\tau_{0 x} & =\rho_{1} C_{B}\left(\bar{u}_{1}^{2}+\bar{v}_{1}^{2}\right)^{1 / 2} \bar{u}_{1}, \\
\tau_{1 x} & =\rho_{1} C_{1}\left[\left(\bar{u}_{1}-\bar{u}_{2}\right)^{2}+\left(\bar{v}_{1}-\bar{v}_{2}\right)^{2}\right]^{1 / 2}\left(\bar{u}_{2}-\bar{u}_{1}\right)
\end{aligned}
$$

with analogous expressions for the $y$-direction. The overbar variable represent the average layer velocity, $C_{B}=2.3 \times 10^{-3}$ is the bottom friction coefficient, and $C_{1}=0.4 \times 10^{-3}$ is the interfacial shear stress coefficient. The value chosen for $C_{B}$ is typical for bottoms with roughness heights of $20-30 \mathrm{~cm}$ and layer thickness of 30-40 m; similar values have been suggested by Thompson and O'Brien (1973) and Hickey and Hamilton (1980). Much less is known about the interfacial stress coefficient in oceanic flows. Average values range from $4 \times 10^{-4}$ to $15 \times 10^{-4}$, Karelse (1974). Previously, O'Brien and Hurlburt (1972) have used the same $\left(0.4 \times 10^{-3}\right)$ to study upwelling. The wind stress is parametrized in the usual way as

$\tau_{2}=\rho_{\text {air }} C_{D}\left|U_{10}\right| U_{10}$

where $\rho_{\text {air }}$ is the air density, $U_{10}$ is the wind speed, measured at a height of $10 \mathrm{~m} \mathrm{MSL}$, and $C_{D}$ is the wind stress drag coefficient, given by

$C_{D}=\left(1.1+0.0536 U_{10}\right) \times 10^{-3}, U_{10}$ in $\mathrm{ms}^{-1}$

as proposed by Wang and Connor (1975). This formulation is slightly different but in general agreement with that proposed by $\mathrm{Wu}(1980)$.

The integrated internal stresses are parametrized as

$F_{\mathrm{ix}_{k} x_{m}}=E_{k m}\left(\frac{\partial q_{\mathrm{ik}}}{\partial x_{m}}+\frac{\partial q_{\mathrm{im}}}{\partial x_{k}}\right) ; \quad i=1,2$

where $x_{1}=x, x_{2}=y$, and $q_{i k}$ is the transport in layer $i$ in the direction $k$, and $E_{k m}$ is an eddy viscosity tensor. The primary function of including the internal momentum transfer terms is to allow some dissipation of short period waves when these arise from the numerical calculations.

The system of equations is solved numerically using a finite element formulation with linear triangular elements for the spatial derivatives and a "split-time" finite difference scheme in time to advance the solution to the 
next time step. A detailed description of these procedures can be found in Wang and Connor (1975).

\section{Results and discussion}

\subsection{Atmospheric model}

3.1.1 Results. The model was run using three-month mean conditions (JFM, AMJ, JAS and OND) in order to investigate the seasonal variations of the sea-breeze circulation. The results refer to the second day of integration. In analyzing the model results, it is important to consider the behavior of the circulation in both north-south (NS) and east-west (EW) directions due to the configuration of the coastline near Cabo Frio (Fig. 1).

The model results show that the winds associated with the sea-breeze reach their maximum intensity about 15:00-16:00 LT in all the periods. Tables 2 and 3 show the seasonal variations of the $u$ and $v$-components of the horizontal wind (at the level of $990 \mathrm{hPa}$ ), respectively, at 15:00 LT. It can be seen that the sea-breeze is more intense in both the EW and SN directions in OND and JFM (where there is upwelling) and weaker in AMJ and JAS (where there is no upwelling), with the maxima occurring near the coast. The seasonal variations of the sea-breeze are in agreement with the seasonal landocean thermal contrast (Table 1), showing that the coastal upwelling plays an important role in regulating the intensity of the local circulation in this region. The strongest sea-breeze occurs in OND, when the coastal upwelling is most intense; in AMJ and JAS, when there is no coastal upwelling, the circulation is weaker.

In order to study the dynamical and thermal effects of coastal upwelling on the sea-breeze circulation in the region of Cabo Frio, OND and AMJ are chosen as the characteristic periods of upwelling and no upwelling, respectively.

Table 2. Seasonal EW variations of the u-component of the horizontal wind (at the level of $990 \mathrm{hPa}$ ), at 15:00 LT, along line AB (Fig. 1). Units are $\mathrm{m} \mathrm{s}^{-1}$

\begin{tabular}{lcccccc}
\hline & $50 \mathrm{~km}$ & $40 \mathrm{~km}$ & $30 \mathrm{~km}$ & $20 \mathrm{~km}$ & $10 \mathrm{~km}$ & Coast \\
\hline JFM & -1.0 & -1.1 & -1.3 & -1.9 & -3.8 & -6.6 \\
AMJ & -0.8 & -0.9 & -1.1 & -1.6 & -3.3 & -5.8 \\
JAS & -0.9 & -1.0 & -1.2 & -1.7 & -3.4 & -6.0 \\
OND & -1.2 & -1.3 & -1.7 & -2.7 & -4.7 & -7.5 \\
\hline
\end{tabular}

Table 3. Seasonal SN variations of the $v$-component of the horizontal wind (at the level of $990 \mathrm{hPa}$ ), at 15:00 LT, along line CD (Fig. 1). Units are $\mathrm{m} \mathrm{s}^{-1}$

\begin{tabular}{llllll}
\hline & $40 \mathrm{~km}$ & $30 \mathrm{~km}$ & $20 \mathrm{~km}$ & $10 \mathrm{~km}$ & Coast \\
\hline JFM & 0.1 & 0.2 & 0.9 & 3.0 & 5.6 \\
AMJ & 0.1 & 0.1 & 0.7 & 2.6 & 5.1 \\
JAS & 0.1 & 0.1 & 0.7 & 2.7 & 5.2 \\
OND & 0.4 & 0.8 & 1.6 & 4.0 & 6.5 \\
\hline
\end{tabular}

Figure 6 shows the development of the horizontal extension of the sea-breeze circulation as a function of time for OND and AMJ. As the LST becomes higher than SST, the sea-breeze starts near the seashore in both the cases. There is a lag between the time of the beginning of the circulation for the two periods. The sea-breeze begins to develop around $1 \mathrm{~h}$ earlier in OND than in AMJ.

With the continued heating of the land, the circulation increases in horizontal extension and progresses landward and seaward, as shown in Fig. 6. The strongest winds occur around 14:00-16:00 LT. Figure 7 shows the cross section of the $\mathbf{u}$ and $\mathbf{v}$-components of the horizontal wind at 15:00 LT. At this time, in AMJ the sea-breeze penetrates $100 \mathrm{~km}$ inland in the EW direction and $20 \mathrm{~km}$ in the SN direction, and reaches a depth of $1250 \mathrm{~m}$ and $900 \mathrm{~m}$ in the EW and SN directions, respectively. The highest values of $\mathbf{u}\left(-5.8 \mathrm{~ms}^{-1}\right)$ and $\mathbf{v}\left(5.1 \mathrm{~m} \mathrm{~s}^{-1}\right)$ occur near the coast. For OND, the easterlies reach $100 \mathrm{~km}$ inland in the EW direction and the southerlies penetrate $30 \mathrm{~km}$ inland in the SN direction. The depth of the circulation is about $1500 \mathrm{~m}$ and $1200 \mathrm{~m}$ in the EW and SN directions, respectively. The strongest winds also occur near the coast: $-7.5 \mathrm{~ms}^{-1}$ (u) and $6.5 \mathrm{~m} \mathrm{~s}^{-1}$ (v). The corresponding cross sections of the vertical velocity are shown in Fig. 8. The maxima in the ascending motions inland in the EW direction are $18.1 \mathrm{~cm} \mathrm{~s}^{-1}$ and $16.2 \mathrm{~cm} \mathrm{~s}^{-1}$ in OND and AMJ, respectively, while in the SN direction the highest values of the vertical velocity are $21.4 \mathrm{~cm} \mathrm{~s}^{-1}$ and $18.4 \mathrm{~cm} \mathrm{~s}^{-1}$ in OND and AMJ, respectively. These results show that the circulation is stronger in OND than in AMJ.

The horizontal distribution of the wind-vector, at the level of $990 \mathrm{hPa}$, at 15:00 LT is shown in Fig. 9. The sea-breeze comes from SE in the areas nearest to the junction of the two coastlines, showing the simultaneous effect of both the $\mathbf{u}$ and $\mathbf{v}$-components of the horizontal wind. For the inland region far from the SN coastline, the effect of the $\mathbf{v}$-component overcomes that of the u-component. The opposite occurs in the inland regions far from the EW coastline. The intensification of the circulation in OND compared to AMJ is also evident.

As the sea-breeze penetrates inland a frontal zone is generated separating the sea-air from the air over land. Figure 10 shows that this frontal zone is more pronounced when there is upwelling (OND).

After the occurrence of its maximum, the sea-breeze continues gradually to increase in horizontal extension in both the periods, although the circulation is more intense in OND (Fig. 6). With the decreased heating of the land surface during the night, the sea-breeze is weakened. Even when the temperatures over land become lower than those over the sea, the overall flow is still directed from sea to land, although the wind speed weakens with the passing of time, as shown in Fig. 6 . The circulation is reversed and a weak land-breeze sets during the early hours of the next day.

These results indicate that the sea-breeze circulation in the Cabo Frio region is intensified during the periods of coastal upwelling. This intensification of the circula- 

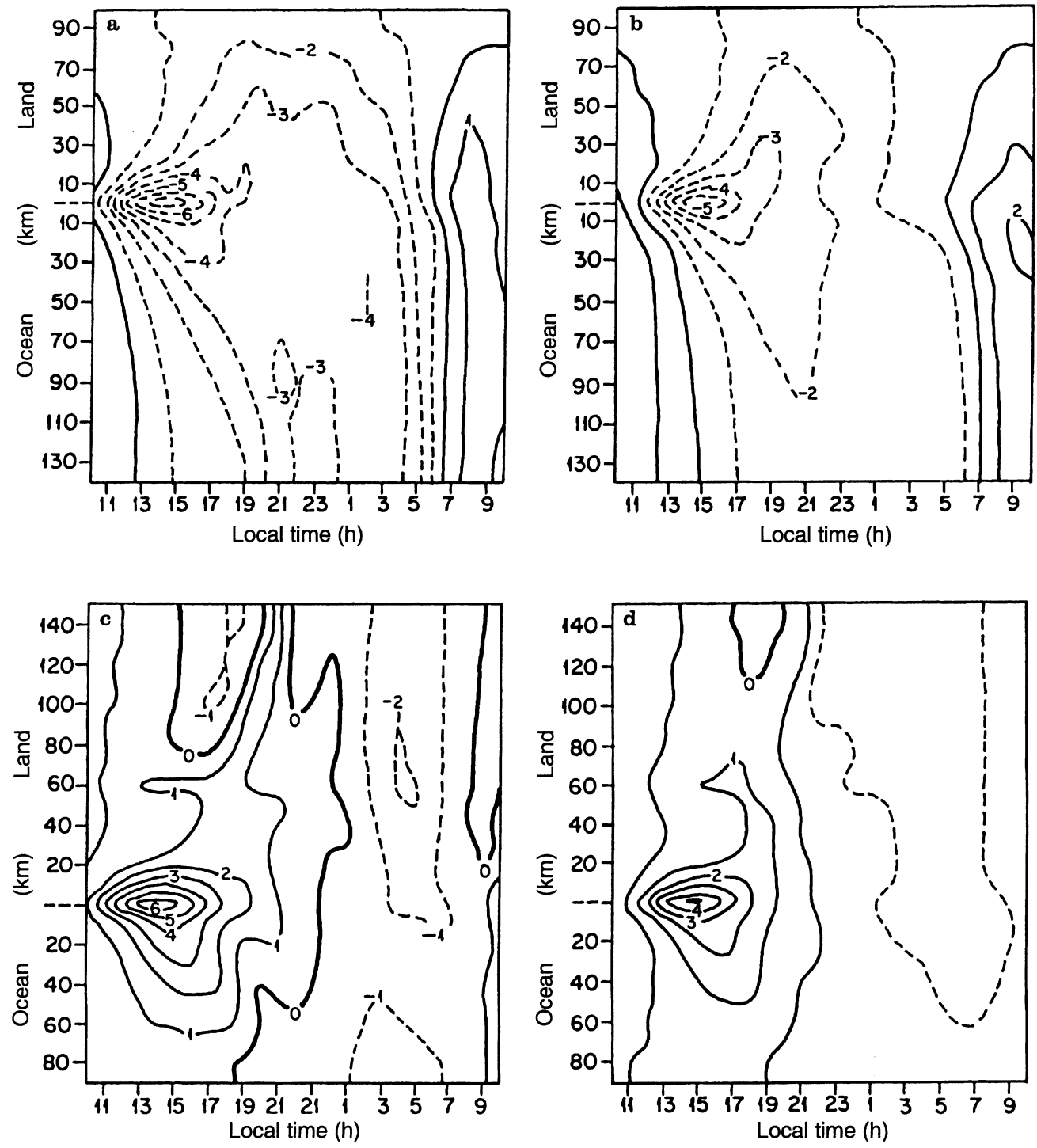

Fig. 6a-d. Simulated temporal variation of the horizontal extension of the sea-breeze at the $990 \mathrm{hPa}$ level: a EW variation of the u-component along line $\mathrm{AB}$ (Fig. 1) simulated for OND.

The easterlies are indicated by broken lines; and the westerlies are represented by solid lines; $\mathbf{b}$ as a, except for AMJ; c SN variation of the $v$-component along line $\mathrm{CD}$ simulated for OND. The southerlies are indicated by solid lines and the northerlies are represented by a broken line; and $\mathbf{d}$ as $\mathbf{c}$, except for AMJ. Units are $\mathrm{m} \mathrm{s}^{-1}$

tion can be seen in its onset, horizontal and vertical extension, and in the magnitudes of the wind.

3.1.2 Comparison with observations. Limited observational data were available for the region of Cabo Frio. In this section the results of the model simulations are compared with the observations. Figure 11 shows the monthly mean surface wind for 10 years (1971-1980) obtained from the Meteorological Station in Cabo Frio. These observations correspond to two hourly mean values of the surface horizontal wind $(10 \mathrm{~m}$ above surface) near the coastal region. As can be noted, the dominant northeasterlies at night tilt towards the zonal direction in the afternoon in all months due to the presence of sea-breeze. Because of the coastline orientation in the region of Cabo Frio (Fig. 1), the sea-breeze blows from east to west along the SN coast and south to north along the EW coast. Also, the larger the magnitude of inclination in the zonal direction of observed horizontal vector wind, the stronger the sea-breeze.
Thus, as noted in Fig. 11, this circulation in general is more intense during the summer months, when the coastal upwelling occurs.

To compare the observations with the model results, means of 3 months (JFM, AMJ, JAS, and OND) were obtained. It should be kept in mind that the model results refer only to the sea-breeze circulation, while the observed wind gives the total wind, i.e. the prevailing wind plus sea-breeze.

Figure 12 shows the seasonal variation of simulated (at $990 \mathrm{hPa}$ ) and observed horizontal wind (10 $\mathrm{m}$ above surface) near the coast at 15:00 LT and 21:00 LT. It can be noted that the simulated sea-breeze is stronger during JFM and OND, which seems to agree with observations. In the observations for these two periods, the horizontal wind-vectors are more inclined in the zonal direction indicating stronger sea-breezes. During the night the sea-breeze circulation weakens and the observed wind blows from northeast.

Regarding the seasonal variation of temperature, the model results are compared with observational data for 

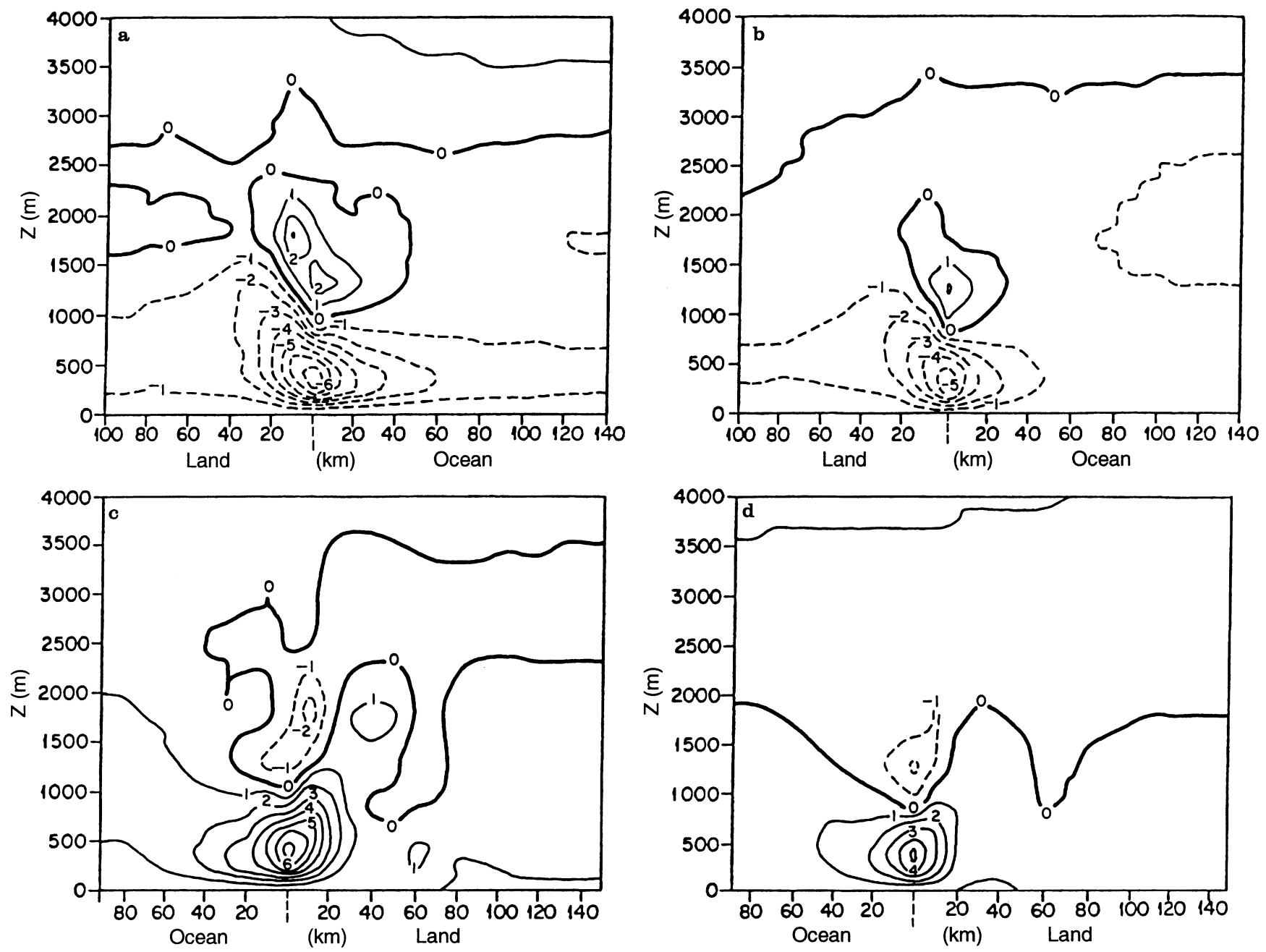

Fig. 7a-d. Cross section of the simulated horizontal wind at 15:00 LT: a EW variation of the $u$-component along line AB (Fig. 1) for OND; $\mathbf{b}$ same as a, except for AMJ; c SN variation of the v-component along line CD (Fig. 1) for OND; and d same as c, except for AMJ. Units are $\mathrm{m} \mathrm{s}^{-1}$

1972 obtained from DHN. Figure 13 shows that the seasonal variation of temperature simulated by the model (at $990 \mathrm{hPa}$ level) is similar to the observed variation near the surface at 15:00 LT and 21:00 LT. In both, a maximum in JFM and a minimum in JAS can be noted.

Next, model results are compared with the observations, considering the two situations: with upwelling (OND) and without upwelling (AMJ). Table 4 shows the simulated values for $\mathbf{u}$ and $\mathbf{v}$ at $990 \mathrm{hPa}$ level and surface observations ( $10 \mathrm{~m}$ above surface) near the coast in these two cases. During the periods OND and AMJ in the observations at 15:00 LT, the easterlies are intensified and northerlies are weakened with respect to the observations at 21:00 LT, showing the presence of the sea-breeze circulation. The sea-breeze is more intense in OND. This feature seems to be well simulated by the model. As Table 4 clearly shows the magnitude of the simulated horizontal winds is larger than the observed values. This is related to the fact that the model results refer to values at $990 \mathrm{hPa}$ and the observations correspond to values at $10 \mathrm{~m}$ above the surface.

Figure 14 and 15 show the simulated (at $990 \mathrm{hPa}$ ) and observed diurnal variation of wind (10 $\mathrm{m}$ above surface) for OND and AMJ. For a better comparison between the model results and observations, an attempt to isolate the sea-breeze from the observed wind is made. This is done assuming that the observed wind is a combination of a mean wind and a perturbation (sea-breeze). Twenty-four hour means of $\mathbf{u}$ and $\mathbf{v}$ for each period are taken as the mean wind. This mean is subtracted from the observed wind for each hour giving the $\mathbf{u}$ and $\mathbf{v}$ values of the sea-breeze. These figures show that the model results are in good agreement with the observations. The sea-breeze intensifies in the afternoon and evening, and weakens during the night. It finally blows in the opposite direction, forming the land-breeze, during the morning of the next day. It can also be noted that the sea-breeze is much stronger than the seabreeze in OND. Comparing Figs. 14b and 15b, it can be noted that the sea-breeze is intensified when upwelling occurs. The simulations show good agreement with observations (Fig. 14a, 15a). A comparison of Figs. 14b and $15 \mathrm{~b}$ shows that the sea-breeze onset and the most intense sea-breeze with upwelling occurs earlier than when there is no upwelling. Model results also show similar features, as commented on in Sect. $3 \mathrm{a}$. 

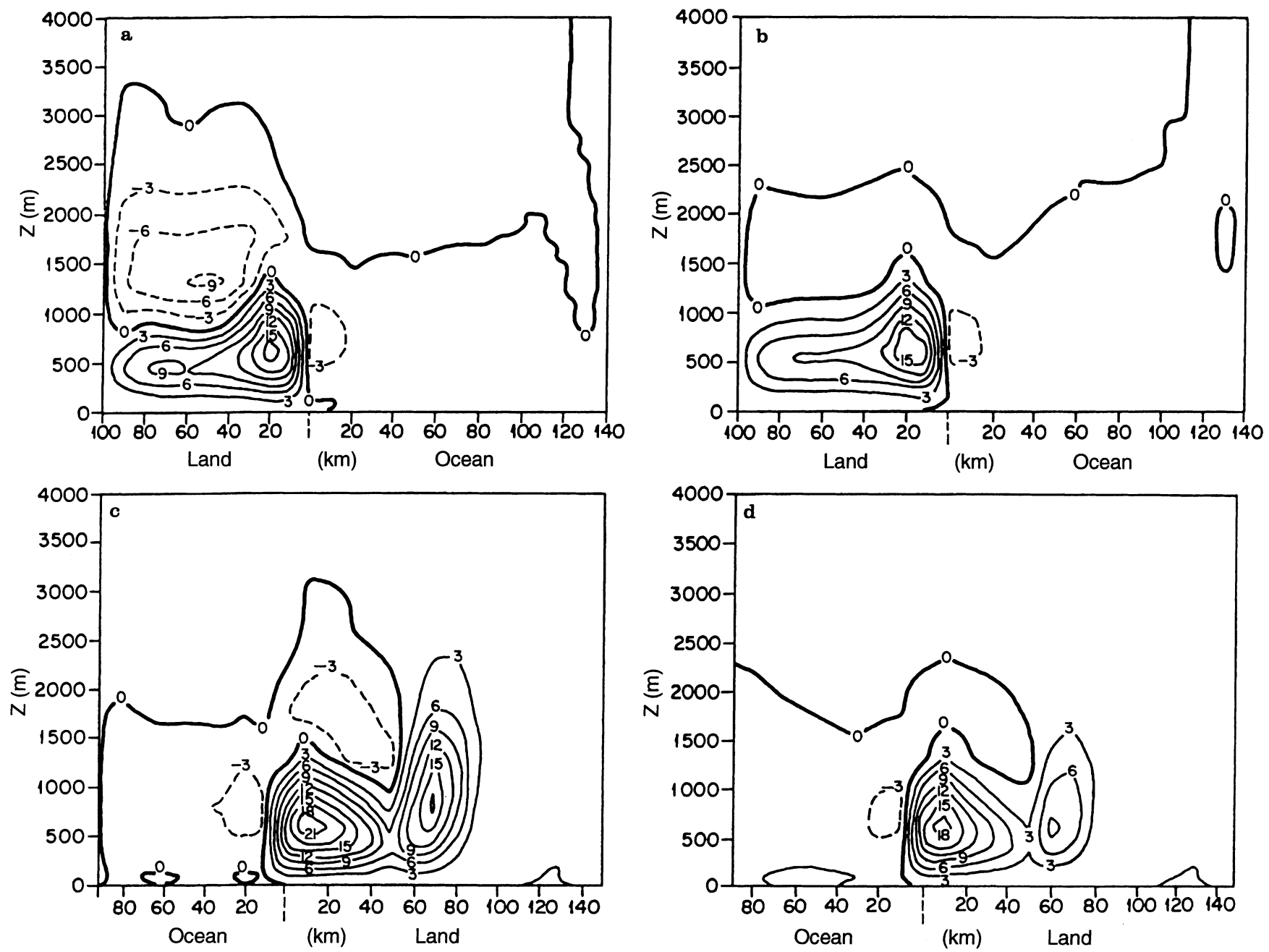

Fig. 8a-d. Cross section of the simulated vertical velocity at 15:00 LT: a $\mathrm{EW}$ variation of $w$ along a line parallel to $\mathrm{AB}$ (Fig. 1) situated $5 \mathrm{~km}$ northward from the EW coastline for OND; $\mathbf{b}$ same as a, except for

$\mathrm{AMJ} ; \mathbf{c} \mathrm{SN}$ variation of $w$ along a line parallel to $\mathrm{CD}$ (Fig. 1) situated $5 \mathrm{~km}$ west ward from the SN coastline for OND; and d same as c, except for AMJ. Units are $\mathrm{cm} \mathrm{s}^{-1}$

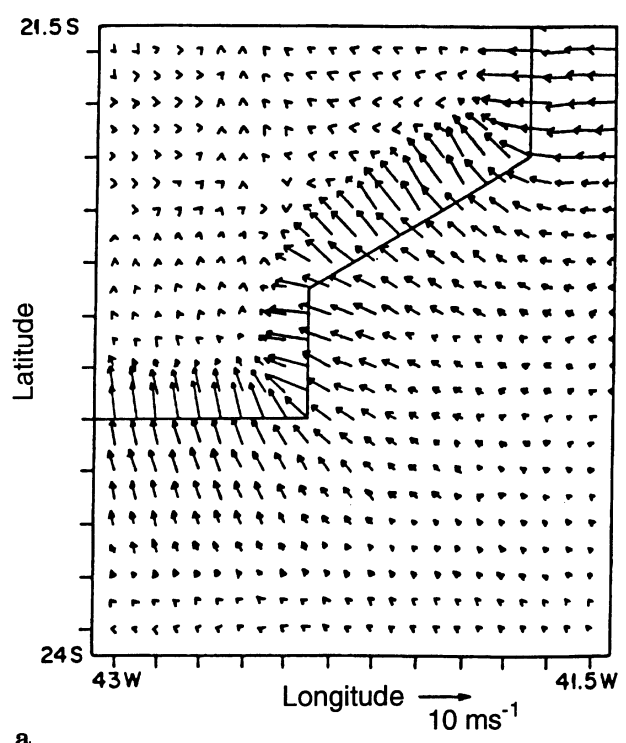

a

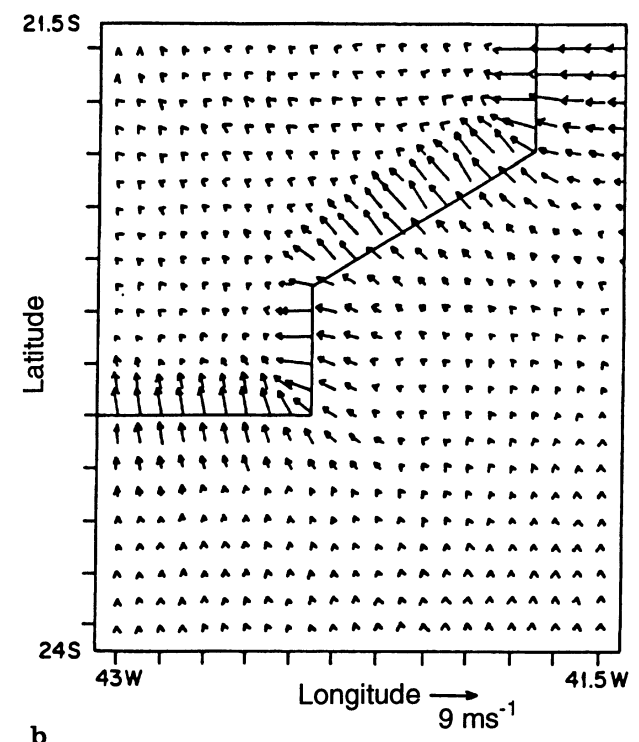

Fig. 9a,b. Simulated horizontal wind-vector (at level of $990 \mathrm{hPa}$ ) at 15:00 LT for: a OND and $\mathbf{b}$ AMJ. Units are $\mathrm{m} \mathrm{s}^{-1}$ 

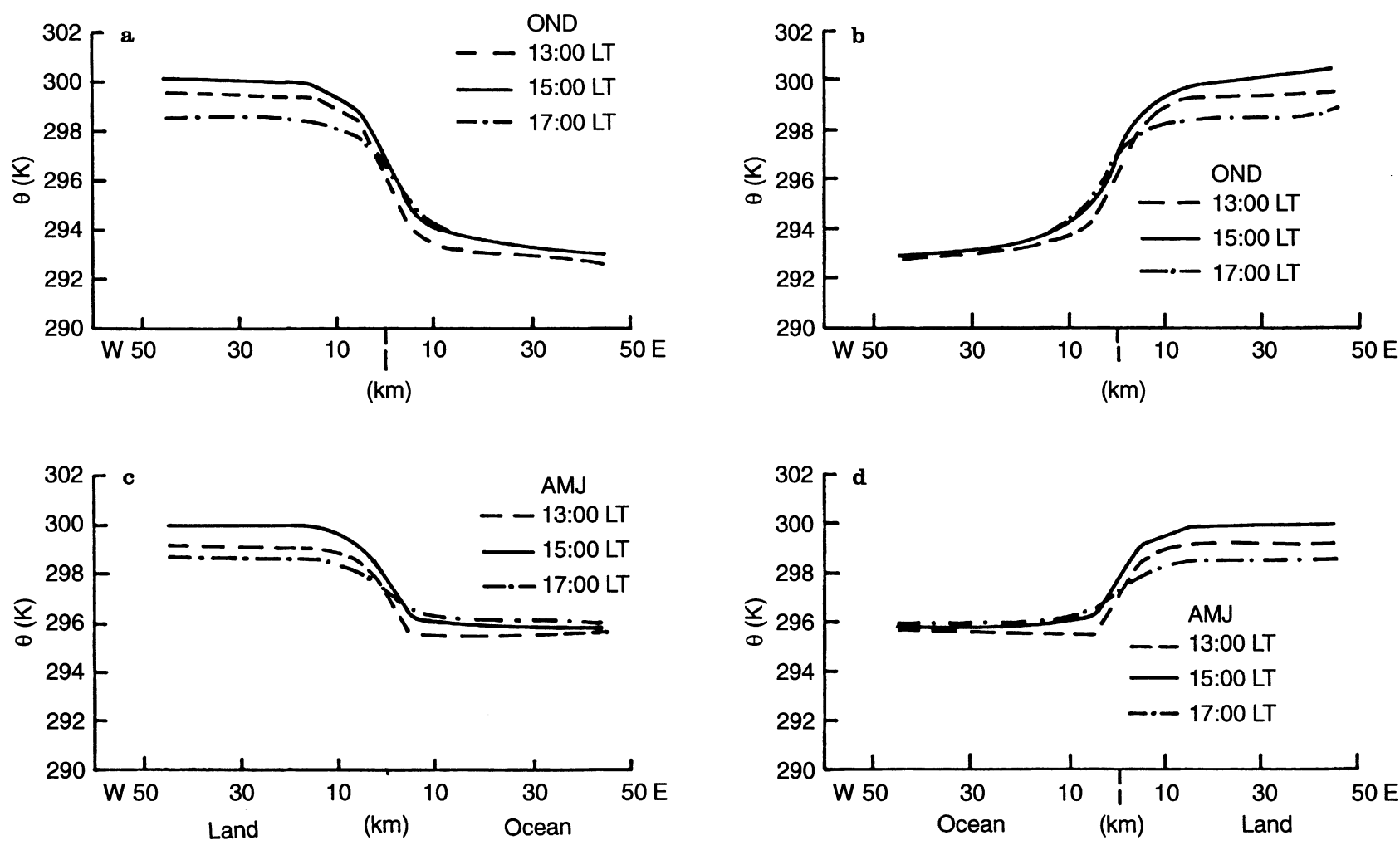

Fig. 10a-d. Horizontal variation of the simulated potential temperature (at level of $990 \mathrm{hPa}$ ) for three time stages: a EW variation along a line parallel to $\mathrm{AB}$ (Fig. 1) situated $5 \mathrm{~km}$ northward from the EW

As shown there is good agreement between the model results and the available observations (Figs. 11-15). However, it should be mentioned that the model equations and parametrizations are made for an idealized situation of land and sea-breezes. Also, the interactions between sea-breeze circulation and the mean wind and the topography are not included. Thus, some differences between observations and model results are expected. Further, the model results and observations are for different levels: $990 \mathrm{hPa}$ for the model and $10 \mathrm{~m}$ above surface for the observed data. Even with these

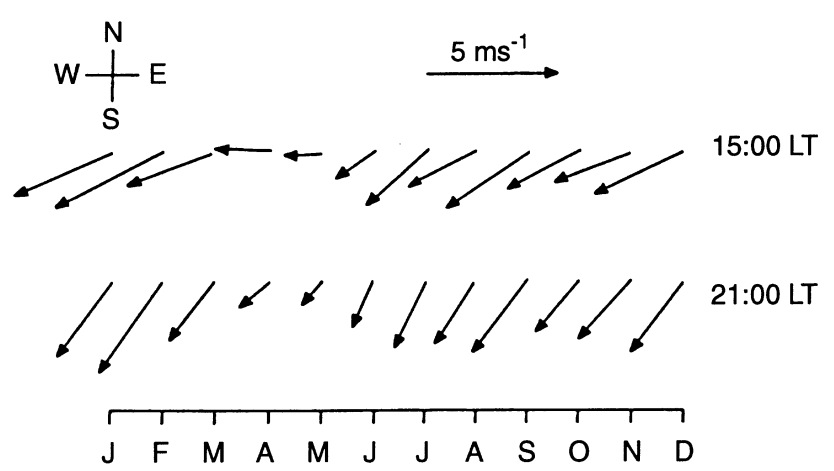

Fig. 11. Monthly mean of the surface horizontal wind-vector $(10 \mathrm{~m}$ above surface) observed near the coast in the Cabo Frio region for 15:00 LT and 21:00 LT. The data are obtained from the Meteorological Station in Cabo Frio (point F in Fig. 1) for ten-year means (1971-1980)

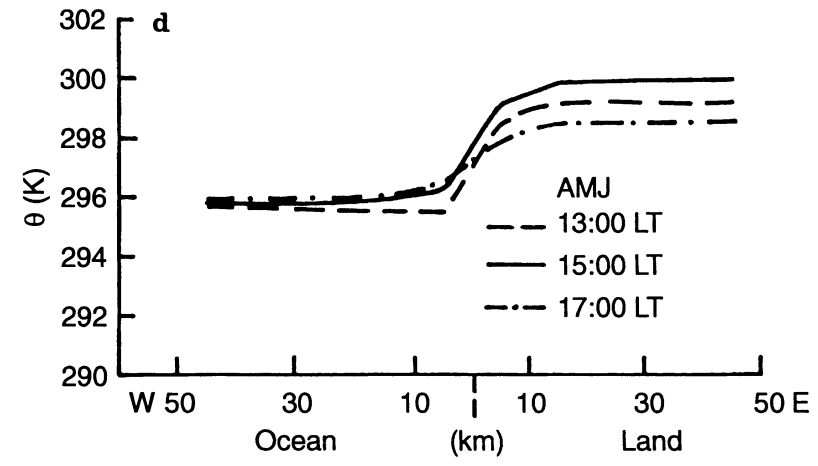

coastline for OND; $\mathbf{b}$ SN variation of potential temperature along a line parallel to $\mathrm{CD}$ (Fig. 1) situated $5 \mathrm{~km}$ westward from the NS coastline for OND; c same as a, except for AMJ; and $\mathbf{d}$ same as $\mathbf{b}$, except for AMJ

limitations there is good agreement between observations and model simulations, which is encouraging. It should be emphasized that we ran the model using observed seasonal values of SST. Thus, the simulated sea-breeze circulation responds to an enhanced temperature forcing which is due to cold water upwelling near the coastal region of Cabo Frio. In the next section, the effect of the enhanced sea-breeze on the upwelling strength is investigated.

\subsection{Ocean model}

In order to estimate the sea-breeze signal over the ocean circulation in the Cabo Frio upwelling region, a simple two-layer coastal numerical model was implemented. Details of this model can be found in Lorenzzetti et al. (1987). The intensity of the upwelling in this oceanic model is determined by the values of the interface anomaly elevations. In a two-layer model, the upwelling is characterized by a decrease of the upper layer thickness which is associated with positive interface anomalies.

The ocean model was run using the surface sea-breeze obtained from the atmospheric model superimposed over a constant wind of $6 \mathrm{~ms}^{-1}$ blowing from NE, representing the prevailing wind without the sea-breeze. This NE prevailing wind is favorable for upwelling throughout the region. For both the N-S and E-W coastline regions, the component of the wind parallel to 


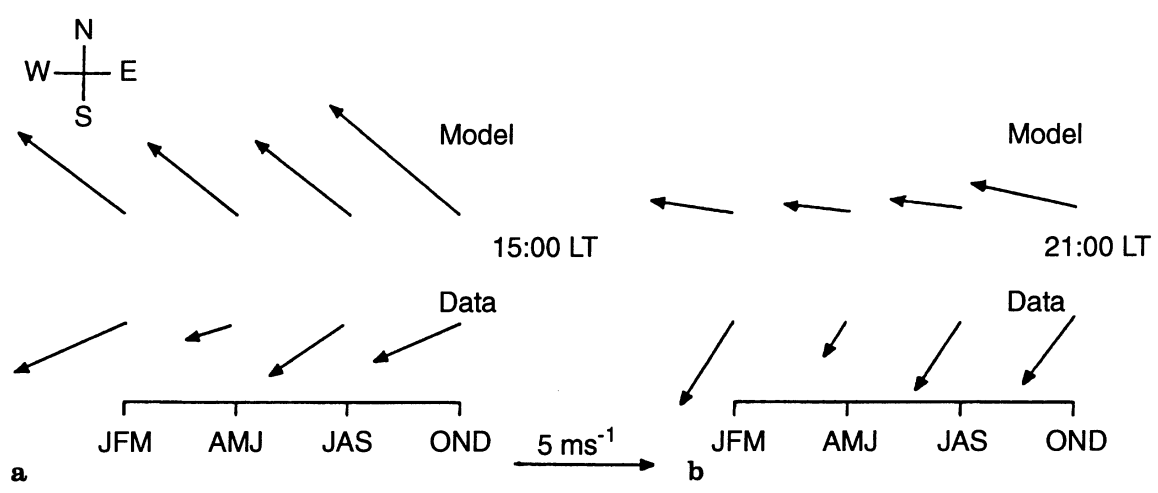

Fig. 12a,b. Simulated and observed three-month averages of the horizontal wind-vector for: a 15:00 LT and b 21:00 LT. The model values refer to the simulated sea-breeze (at level of $990 \mathrm{hPa}$ ) at a gridpoint situated inland $10 \mathrm{~km}$ from both the SN and EW coastlines

(point $\mathrm{E}$ in Fig. 1); and the data correspond to surface wind observations (10 $\mathrm{m}$ above surface) near coast for ten-year means (1971-1980) obtained from the Meteorological Station in Cabo Frio (point $\mathrm{F}$ in Fig. 1). Units are $\mathrm{m} \mathrm{s}^{-1}$

the coast is favorable for upwelling, since the Ekman transport is to the left of the wind direction. The first 24 $\mathrm{h}$ of integration was made using only the constant $6 \mathrm{~m} \mathrm{~s}^{-1} \mathrm{NE}$ winds and starting from rest. A two hour ramp was used at the beginning of the integration to bring the wind from zero to $6 \mathrm{~m} \mathrm{~s}^{-1}$ normal intensity. Two other experiments were completed separately to verify the effects of sea-breeze on the intensification and change of direction of the prevailing wind. The first one used a constant direction wind with its magnitude modulated by the sea-breeze. The second one used a constant intensity $6 \mathrm{~m} \mathrm{~s}^{-1}$ wind but with a direction varying according with the sea-breeze effect.

The ocean model is implemented for this region using a linear triangular grid composed of 740 elements and 432 nodes. At each node, the local mean depth was determined through an interpolation of a Nautical Chart of the Brazilian Navy. The following parameters

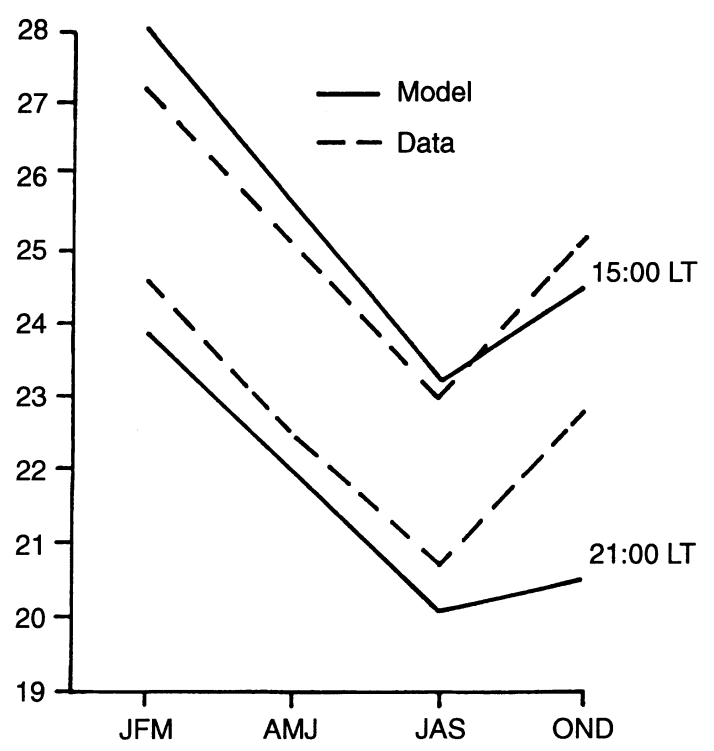

Fig. 13. Simulated and observed three-month averages of the temperature at 15:00 LT and 21:00 LT. The model values refer to the simulation at the level of $990 \mathrm{hPa}$ at a gridpoint situated $5 \mathrm{~km}$ inland from both the SN and EW coastlines; and the data correspond to air surface values near coast for 1972 (DHN). Units are ${ }^{\circ} \mathrm{C}$ were used in all experiments: time step of integration $\Delta t=60 \mathrm{~s} ; \quad \rho_{1}=1025.5 \mathrm{~kg} \mathrm{~m}^{-3} ; \quad \rho_{2}=1022.5 \mathrm{~kg} \mathrm{~m}^{-3}$; $f=-0.533 \times 10^{-4} \mathrm{~s}^{-1}$, corresponding to the latitude of $21.5 \mathrm{~S}$. At time zero the upper layer thickness is constant and equal to $20 \mathrm{~m}$. At the coastal boundary, normal flow is set to zero for both layers and a slip condition is applied to the alongshore flow. For the specification of boundary conditions along the open boundaries, extensive testing showed that the best results were obtained by implementation of a sponge layer at the north and south extremes of the domain. These two layers effectively absorbed most of the wave energy near these boundaries. The rationale of the sponge layer implementation is explained in Lorenzzetti and Wang (1986). Adiabatic boundary conditions, i.e., fixed surface and interface elevations, were used along the offshore boundary, represented in the model by the $150 \mathrm{~m}$ isobath, corresponding to the continental shelf break in the region. A time ramp of $2 \mathrm{~h}$ was used on the wind stress forcing in the beginning of all experiments in order to avoid shocking the model. The numerical model was integrated for $72 \mathrm{~h}$ in all experiments.

In order to serve as a comparison, a first model run was made using a constant wind of $6 \mathrm{~m} \mathrm{~s}^{-1}$ from NE, representing the prevailing wind of this region. A second experiment was carried out using a constant $6 \mathrm{~m} \mathrm{~s}^{-1} \mathrm{NE}$ wind for the first $24 \mathrm{~h}$ followed by a vector composition of this wind with the summertime sea-breeze wind signal obtained from the atmospheric model for $200 \mathrm{~m}$ height and reduced to surface through a logarithmic interpolation. Two auxiliary experiments were also carried out in a similar manner as the second experiment: the first one keeping the direction of the summertime sea-breeze signal constant and NE, and the second one keeping the intensity of the wind equal to $6 \mathrm{~m} \mathrm{~s}^{-1}$ but varying its direction in accordance with the sea-breeze. These two last experiments were carried out to verify the separate effects of direction and intensity modification introduced by the sea-breeze on the prevailing wind, and consequently on the upwelling strength. No simulations of the effect of the sea-breeze wind on the upwelling were carried out for wintertime conditions since there is no upwelling during this season. 
Table 4. Values of $u$ and $v$-components of the horizontal wind at 15:00 LT and 21:00 LT for OND and AMJ: a simulated at a gridpoint inland situated $10 \mathrm{~km}$ from both the $\mathrm{SN}$ and EW coastlines (point E in Fig. 1) at the level of $990 \mathrm{hPa}$; b observed
$10 \mathrm{~m}$ above surface. The data are obtained from the Meteorological Station in Cabo Frio (point F in Fig. 1) for 10-y means, 19711980. Units are $\mathrm{m} \mathrm{s}^{-1}$

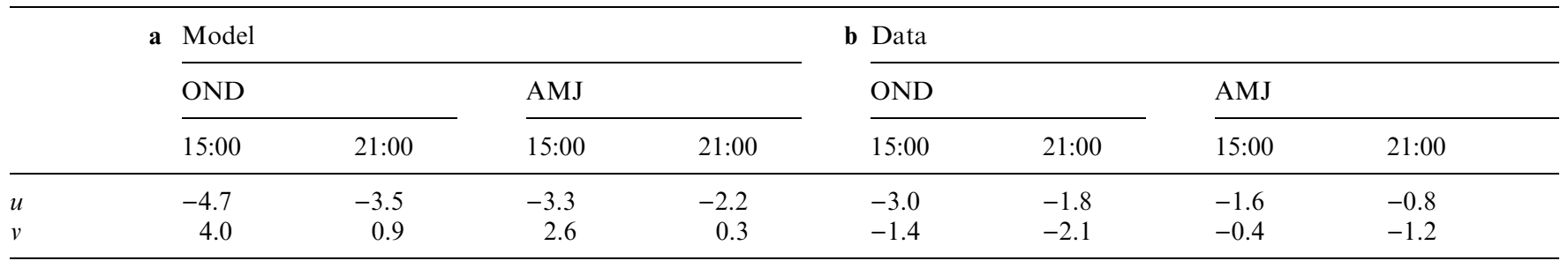

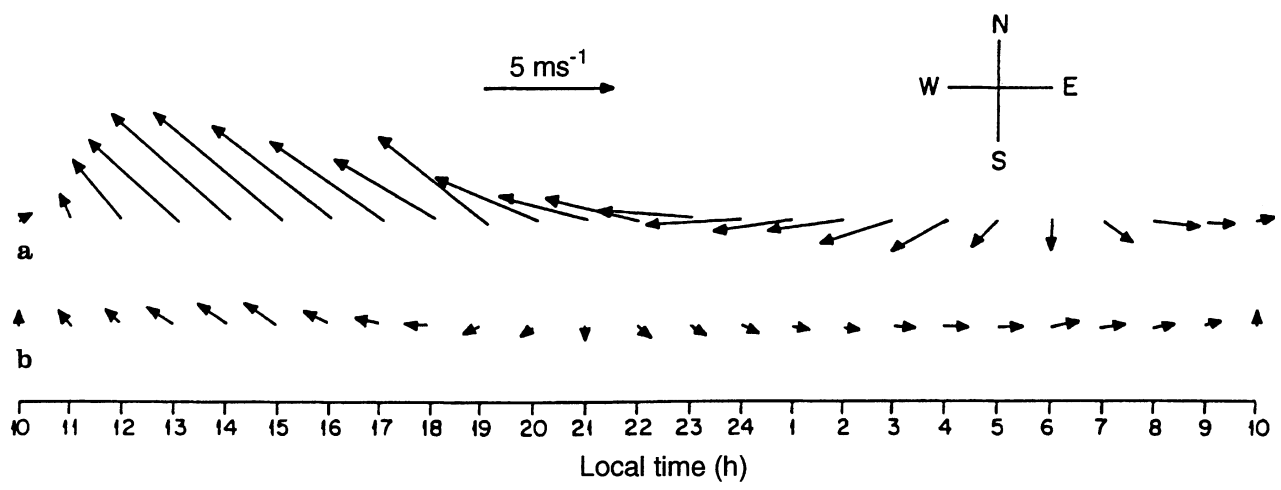

Fig. 14a,b. Simulated and observed diurnal variation of the seabreeze for an upwelling case: a simulated values for OND, at $990 \mathrm{hPa}$, at a grid point situated inland $10 \mathrm{~km}$ from both the SN and EW coastlines (point $\mathrm{E}$ in Fig. 1); and b observed values (10 $\mathrm{m}$ above

Figure 16 shows the time series of interface anomalies for summertime conditions and for the four different experiments described before. Cases $a$ and $b$ correspond to two points located near the coast and in the vicinity of Cabo Frio and Cabo de São Tomé, respectively. These two points were chosen in areas known as maximum intensity cores of the upwelling signal in the region. For both locations, Fig. 16 shows growing positive interface anomaly values characteristic of upwelling. With the inclusion of the sea-breeze signal after $24 \mathrm{~h}$ of integration, it is possible to see a substantial enhancement of the upwelling, corresponding to increases of approximately $6 \mathrm{~m}$ for Cabo Frio and $4 \mathrm{~m}$ surface) near coast for OND (10 y means, 1971-1980) obtained from the Meteorological Station in Cabo Frio (point F in Fig. 1). Units are $\mathrm{m} \mathrm{s}^{-1}$

for Cabo de São Tomé of additional elevation of the interface (broken line).

For both places, the increase of the upwelling caused by the sea-breeze seems to be associated mostly with an increase in intensity of the wind. This point can be observed by the short dashed-dot lines representing the case in which the forcing contains the NE basic wind plus the sea-breeze signal, but keeping the NE direction fixed and allowing only the modulation of the wind strength.

The case in which we make the sea-breeze effective only in the direction of the basic wind but keeping its original strength unaltered can be observed in Fig. 16a, $\mathrm{b}$ by the long dashed-dot lines. For Cabo Frio, the

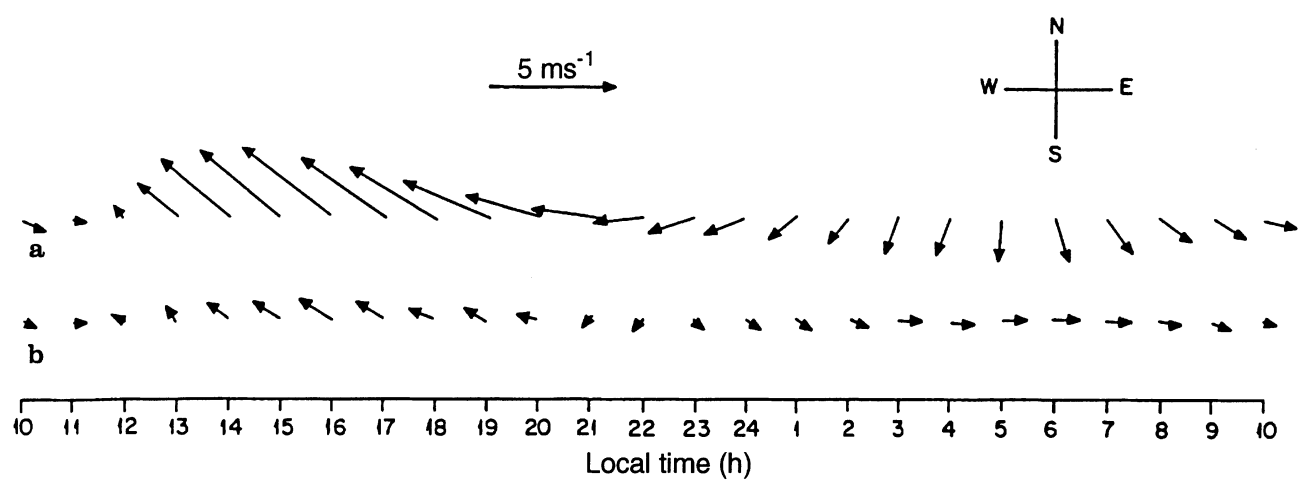

Fig. 15a,b. The same as Fig. 14, except for a non upwelling case. The simulations and observations correspond to AMJ 


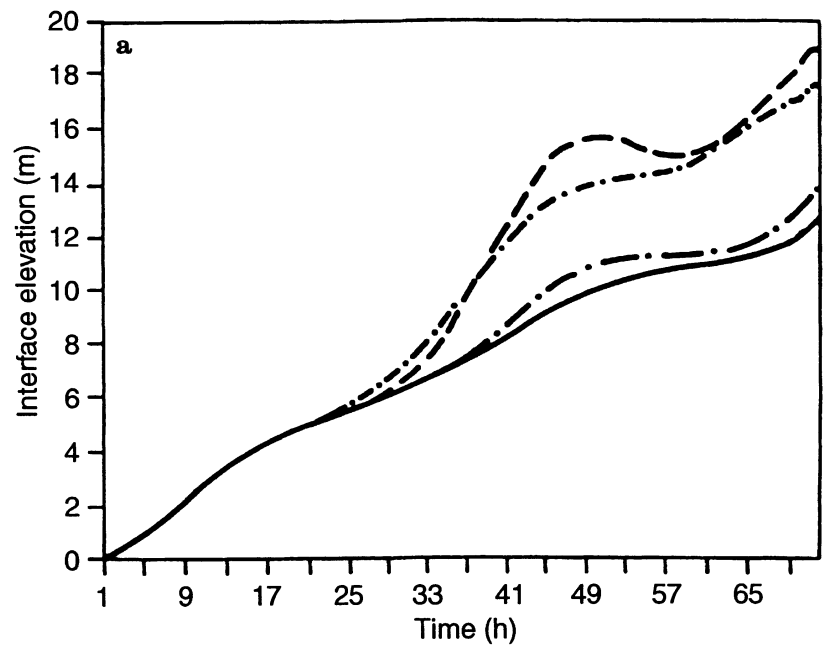

Fig. 16a,b. Time series of interface anomaly elevations obtained from the ocean model. $\mathbf{a}$ and $\mathbf{b}$ refer to summertime conditions and to grid points located near the coast in the vicinity of Cabo Frio and Cabo de São Tomé, respectively. Solid line: constant NE wind; broken line: full

change of wind direction clearly results in a small increase in the upwelling, resulting from a better alignment of the wind with the coastline. Notice in Fig. 9a that near Cabo Frio, the sea-breeze wind vectors contain a favorable component for upwelling. This is caused by the abrupt change of coastline orientation, making the sea-breeze wind not perfectly normal to the coast. On the other hand, the change of wind direction produced by the sea-breeze at Cabo de São Tomé is verified as having a negative effect on the upwelling. This could be associated with the fact that the coastline orientation in this region is mostly parallel to the basic NE wind. The change of direction produced by the seabreeze tends to make the wind less parallel to the coast, resulting in a weakening of the upwelling.

\section{Summary and conclusions}

This work investigates the role of the coastal upwelling in modulating the sea-breeze circulation and the feedback of the sea-breeze on the upwelling signal at Cabo Frio (Brazil).

A three-dimensional numerical model of primitive equations is utilized in a study of the effect of coastal upwelling on sea-breeze circulation. Seasonal variation of atmospheric circulation is investigated by conducting numerical experiments forced by three-month means of observed SST in this region: JFM, AMJ, JAS and OND. In all cases the sea-breeze is most intense offshore but near the coast. Model results show that the sea-breeze is stronger in OND and JFM, when upwelling occurs, and weaker in AMJ and JAS, when there is no upwelling. Observations show a similar behavior.

The intensification of the simulated sea-breeze with the occurrence of upwelling can be noted in the higher values of the horizontal wind, larger horizontal and vertical extensions and stronger vertical motion over the continent.

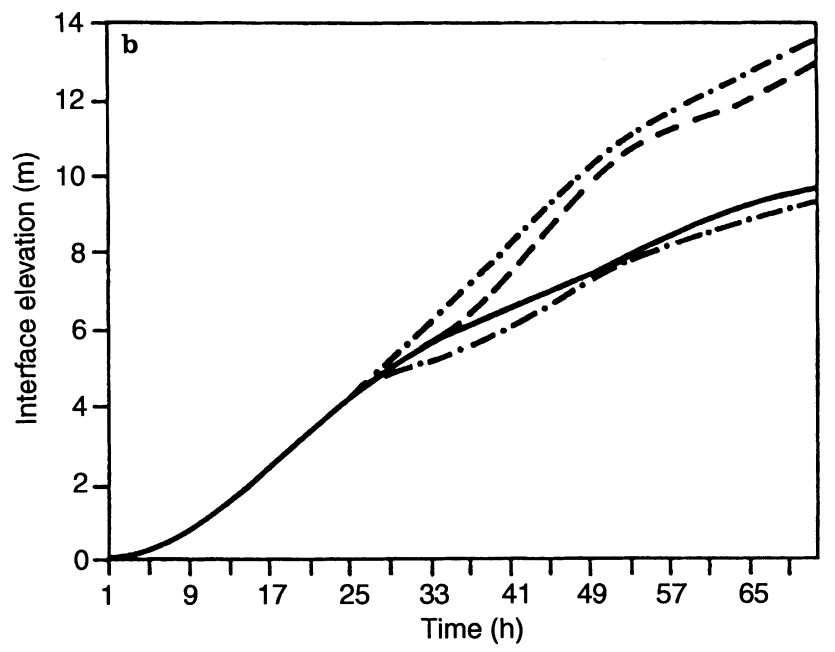

sea-breeze signal after $24 \mathrm{~h}$ of integration; short dashed-dot line: seabreeze signal with NE constant direction after $24 \mathrm{~h}$ of integration; long dashed-dot line: sea-breeze signal with constant magnitude after $24 \mathrm{~h}$ of integration

Numerical simulations and observations also show that there is a difference in the initiation of the seabreeze and the maxima values in the situations with and without upwelling. In the case with upwelling, the seabreeze develops and attains its maximum intensity earlier than the case without upwelling.

A general agreement is observed between the atmospheric model results and observations, which show an intensification of sea-breeze circulation in the afternoon and evening when the upwelling occurs. This intensification of the sea-breeze makes the direction of the wind, which is mostly northeast, become more zonal. Where no upwelling occurs, the sea-breeze is weak.

The results of the oceanic model forced with the seabreeze wind field generated by the atmospheric model show that the upwelling is enhanced by the sea-breeze. The main reason for this enhancement is associated with the intensification of the prevailing wind caused by the sea-breeze. At Cabo Frio, a secondary reason is related to the change of orientation of the prevailing wind forced by the sea-breeze. In Cabo de São Tomé, this effect is negative, that is, the change of wind direction produced by the sea-breeze causes a decrease in the upwelling strength.

In summary, the atmospheric model results and observations show that upwelling has an important role in regulating the sea-breeze circulation in Cabo Frio (Brazil). The sea-breeze is intensified by an enhanced temperature forcing which is due to cold water upwelling near coast. The ocean model results show that this coastal upwelling is enhanced by the sea-breeze circulation. Thus, it is suggested that there is a positive feedback between sea-breeze and coastal upwelling in this region. Although these results are obtained by using two separate models (one atmospheric and the other oceanic), they constitute a pioneering attempt in modeling the feedback effect between sea-breeze and coastal upwelling in this region. 


\section{Appendix: List of symbols}

\section{Atmospheric model}

$C p \quad$ specific heat of dry air at constant pressure

$f \quad$ Coriolis parameter

$f(t) \quad$ forcing function at land surface

FT temporal rate of $\left(p^{*} T\right)$ due to lateral and vertical diffusion

$F \mathbf{U}$ frictional acceleration in $x$ direction

$F \mathbf{V}$ frictional acceleration in $y$ direction

$g \quad$ acceleration due to gravity

$H \quad$ depth of the unstable layer

$K_{h} \quad$ eddy diffusion coefficient of heat

$K_{m} \quad$ eddy diffusion coefficient of momentum

1 mixing-length

$p \quad$ pressure at some level of model

$p_{s} \quad$ surface pressure

$p_{t} \quad$ pressure at the top of the model

$p^{*} \quad p_{s}-p_{t}$

$R \quad$ gas constant for dry air

$t \quad$ time

$t_{0} \quad$ initial time of integration

$T$ temperature

u component of the horizontal velocity

in $x$ direction

$\mathbf{v}$ component of the horizontal velocity

in $y$ direction

V horizontal wind-vector

$x \quad$ horizontal coordinate oriented from west to east

$y$ horizontal coordinate oriented from south to north

$z \quad$ vertical coordinate

$w \quad$ vertical velocity, $\mathrm{d} z / \mathrm{d} t$

$\alpha \quad K_{h} / K_{m}$

$\phi \quad$ geopotential

$\eta \quad p^{*}$ or $\phi$ in Eq. (15), and the prognostic variables in equation 16

$\theta \quad$ potential temperature

$\theta_{a} \quad$ a constant representing potential temperature $(290 \mathrm{~K})$

$\sigma \quad$ vertical coordinate defined by $\left(p-p_{t} /\left(p_{s}-p_{t}\right)\right.$

$\dot{\sigma} \quad$ vertical velocity: $\mathrm{d} \sigma / \mathrm{d} t$

$\tau \quad$ period of one day

$\omega \quad$ vertical velocity: $\mathrm{d} p / \mathrm{d} t$

$\xi \quad$ constant equal 0.2495

(n) time step

$\Delta x \quad$ grid interval in $x$ direction

$\Delta y \quad$ grid interval in $y$ direction

\section{Ocean model}

$f \quad$ Coriolis parameter

$g \quad$ acceleration due to gravity

$\rho_{1}, \rho_{2}$ lower and upper layer density, respectively

$H$ layer thickness

$E_{k m} \quad$ eddy viscosity coefficient

$p_{0} \quad$ pressure at the bottom

$p_{1} \quad$ pressure at the interface

$p_{2} \quad$ pressure at the surface

$t \quad$ time $u \quad$ average layer velocity in $x$ direction

$v \quad$ average layer velocity in $y$ direction

$q_{x} \quad$ layer integrated volume transport in the $x$ direction

$q_{y} \quad$ layer integrated volume transport in the $y$ direction

$x \quad$ horizontal coordinate oriented from west to east

$y$ horizontal coordinate oriented from south to north

$\xi_{0} \quad$ bottom elevation

$\xi_{1} \quad$ interface elevation

$\xi_{2} \quad$ surface elevation

$\tau_{0} \quad$ bottom stress

$\tau_{1} \quad$ interface stress

$\tau_{2} \quad$ surface wind stress

$F_{x x}, F_{y x}$

$F_{y y} \quad$ internal momentum exchange coefficients

$F_{i p} \quad$ pressure stress

$C_{1} \quad$ interface stress coefficient

$C_{B} \quad$ bottom friction coefficient

$\rho_{\text {air }} \quad$ average air density

$C_{D} \quad$ wind stress drag coefficient

Acknowledgements. The authors wish to thank the FAPESP (Foundation for the Support of Research of São Paulo State), for the financial support of COINT project; Dr Merritt R. Stevenson, of INPE, for discussing and improving the manuscript, Carlos L. da Silva Jr for processing the satellite infrared image presented in this paper, and to Regina R. Rodrigues for helping with the oceanic model runs.

Topical Editor D. Y. Webb thanks R. P. Pearce and another referee for their help in evaluating this paper.

\section{References}

Anthes, R. A., The height of the planetary boundary layer and production of the circulation in a sea-breeze model, J. Atmos. Sci., 35, 1231-1239, 1978.

Anthes, R. A., and T. T. Warner, Development of hydrodynamic models suitable for air pollution and other mesometeorological studies, Mon. Weather Rev., 106. 1043-1078, 1978.

Blackadar, A. K., The vertical distribution of wind turbulent exchange in a neutral atmosphere, J. Geophys. Res., 67, 30953102, 1962.

Brown, J. A., and K. A. Campana, An economical time-differencing system for numerical weather prediction, Mon. Weather Rev., 106, 1125-1136, 1978.

Chandrasekhar, S., Hydrodynamic and hydromagnetic stability, Oxford University Press, 1961.

Franchito, S. H., and V. E. Kousky, A numerical model for the simulation of the local circulations applied to the northeast Brazil coastal regions (in Portuguese), Ciên. Cult. (São Paulo) 34, 1484-1498, 1982.

Gaeta, S. A., O. L. Brino, and S. M. M. S. Ribeiro, Distributions of nitrate, chlorophyll $a$, and primary productivity in the southwestern region of the South Atlantic during summer, Southwestern Atlantic Physical Oceanography Workshop Report, Ed. E. Campos, pp. 57-60, 1994.

Hickey, B., and P. Hamilton, A spin-up model as a diagnostic tool for interpretation of currents and density measurements on the continental shelf of the Pacific Northwest, J. Phys. Oceanogr., 10, 12-24, 1980.

Humi, L., and J. A. Lorenzzetti, Use of AVHRR images to study of Cabo Frio wind driven upwelling, Seminar on the use of AVHRR data for meteorological and oceanographic applications, University of Dundee, Scotland, 1991. 
Karelse, M., Momentum and mass transfer in stratified flows, R880, Delft Hydraulics Laboratory, 1974.

Kousky, V. E., Diurnal rainfall variability in Northeast Brazil, Mon. Weather Rev., 108, 488-498, 1980.

Lorenzzetti, J. A., and J. D. Wang, On the use of wave absorbing layers in the treatment of open boundaries in numerical coastal circulation models, Appl. Math. Model. 10(5), 339-345, 1986.

Lorenzzetti, J. A., J. D. Wang, and T. N. Lee, Summer upwelling on the Southeastern Continental Shelf of the USA during 1981, Prog. Oceanog. 19, 313-327, 1987.

Lorenzzetti, J. A., K. Tanaka, and J. D. Wang, Numerical simulation of the coastal upwelling in Cabo Frio using a twolayer finite element model, available in Portuguese: São José dos Campos, INPE, INPE-4502-RPE/561), 1988.

Lu, R., and R. P. Turco, Air pollutant transport in a coastal environment. Part 1: Two-dimensional simulations of sea-breeze and mountain effects, J. Atmos. Sci., 51, 2285-2308, 1994.

Miranda, L. B., Analysis of the water mass on the continental shelf and adjacent oceanic region: from Cabo de São Tomé (RJ) to Ilha de São Sebastião (SP), (available in Portuguese: Dissertação de Livre Docência, Instituto Oceanográfico da Universidade de São Paulo), 123 p., 1982.

O'Brien, J. J., and H. Hurlburt, A numerical model of coastal upwelling, J. Phys. Oceanogr., 2, 14-26, 1972.

Ookouchi, Y., M. Uriu, and R. Sawada, A numerical study on the effects of a mountain on the land and sea breezes, J. Meteorol. Soc. Japan, 56, 368-385, 1978.
Ramos, R. P. L, Precipitation characteristics in northeast Brazil dry region, J. Geophys. Res., 80, 1665-1677, 1975.

Shuman, F. G., Resuscitation of an integration procedure, NMC Office, Note 54, 1971.

Stech, J. L., and J. A. Lorenzzetti, The response of the South Brazil Bight to the passage of wintertime cold fronts, J. Geophys. Res., 97, (C6) 9507-9520, 1992.

Stech, J. L., J. A. Lorenzzetti, and C. L. da Silva Jr., Observação por satélite da ressurgência de Cabo Frio, Memórias do VII Simpósio Latinoamericano de Perceptión Remota, Puerto Vallarta, México, pp. 269-275, 1995.

Thompson, J. D., and J. J. O'Brien, Time dependent coastal upwelling, J. Phys. Oceanogr., 3, 33-46, 1973.

Valentin, J. L., Analyses des parametres hydrobiologiques dans la remontée de Cabo Frio (Brésil), Mar. Biol. 82, 259-276, 1984.

Wang, J. D., and J. J. Connor, Mathematical modeling of near coastal circulation, R. M. Parsons Laboratory Tech. Rep. 200, MIT, 1975.

Wu, J., Wind-stress coefficients over sea surface near neutral conditions- a revisit, J. Phys. Oceanogr., 10, 727-740, 1980.

Yamamoto, G., Theory of turbulent transfer in non-neutral conditions, J. Meteorol Soc. Japan, 37, 60-70, 1959. 